ESTUDIOS 

REVISTA DE DERECHO UNED, NÚM. 12, 2013

\title{
RECLAMACIÓN DE ALIMENTOS EN FAVOR DE HIJOS MAYORES DE EDAD Y EMANCIPADOS. REVISIÓN DE SU RÉGIMEN JURÍDICO, REQUISITOS Y EXTINCIÓN DE LA OBLIGACIÓN LEGAL
}

\author{
«SUPPORT PAYMENTS IN FAVOUR OF LEGAL AGE AND \\ EMANCIPATED CHILDREN. REVIEW OF LEGAL REGULATION, \\ REQUIREMENTS AND EXPIRY OF LEGAL DUTY2
}

\section{ENCARNACIÓN ABAD ARENAS ${ }^{1}$}

Becaria de Investigación del Departamento de Derecho Civil UNED

Resumen: El objeto del presente trabajo es analizar la prestación alimenticia a favor de los hijos mayores de edad o emancipados, prevista por el párrafo segundo del artículo 93 CC -según la redacción dada por Ley 11/1990, de 15 de octubre, sobre reforma del CC, en aplicación del principio de no discriminación por razón de sexo-- Reforma que ha pretendido dar una solución a la problemática suscitada por el régimen anterior, circunscrita a menores de edad. Este párrafo -que no ha supuesto una adaptación del CC al principio de no discriminación por razón de sexo-, introduce una norma de carácter procesal que permite en los procesos matrimoniales regular los alimentos de estos hijos de forma conjunta con las medidas complementarias derivadas de la situación de la crisis de pareja. Examinaremos los pre-

\footnotetext{
1 Este trabajo es uno de los resultados del Programa de promoción de la investigación de la UNED en calidad de Personal de Investigación en Formación, del Departamento de Derecho civil de la UNED, dirigido por el Catedrático Prof. Carlos Lasarte Álvarez, siendo la Directora de dicha Beca la Profesora M. ${ }^{a}$ Fernanda Moretón Sanz, queriendo dejar testimonio de mi agradecimiento a ambos por su apoyo constante y muy especialmente por la revisión de este trabajo y su permanente dedicación a mi formación doctoral por parte de mi Directora, discípula del Prof. Lasarte.
} 
supuestos exigidos para reclamar dichos alimentos, deteniéndonos en aquellos casos donde se mantiene la pensión por la concurrencia de los requisitos legales, teniendo en cuenta la doctrina jurisprudencial partidaria de establecer un límite temporal a su vigencia si concursan determinadas circunstancias. Adicionalmente nos detendremos en el artículo 146 CC y la cuantía de la obligación, teniendo presente que estará en función de las necesidades del hijo y de la proporción en que deberán contribuir los obligados a prestarla. Subrayaremos la novedad introducida el TS sobre quién ha de ser parte en los procesos matrimoniales, en virtud de la cual el único legitimado para reclamar la pensión en favor de los hijos mayores de edad es el progenitor conviviente. Finalmente, nos detendremos en alguno de los supuestos en que podría tener lugar la extinción de la obligación alimenticia establecida a favor de los hijos mayores de edad.

Palabras clave: Alimentos legales; Mayoría de edad; procesos matrimoniales.

Abstract: The aim of this essay is to analyze child support payments in favor of legal age and emancipated children, according to the provisions of Article 93, second paragraph of Civil Code -as worded in Law 11/1990 of October 15th, about Civil Code reform implementing non-discrimination because of sex principle-. This reform has tried to give a solution to the problematic issues caused by the previous legal regime, limited to minor children. This paragraph -that hasn't adapted the Civil Code to non-discrimination because of sex principle-, introduces a procedural regulation that allow to fix child support payments jointly with complementary measures on matrimonial trials. We will study the demanding requirements to claim these payments, going deep in those cases in which the payment is maintained because of the combination of legal requirements, according to jurisprudence in favor of establish a time limit to its validity if certain circumstances occur. We also deepen on Article 146 Civil Code and the amount of payment, having in mind that this amount will be fixed depending on child needs and the proportion in which the liable parties must contribute. We will emphasize the change introduced by the Supreme Court about who has to be part of matrimonial trials, by virtue of which the sole authorized to claim the payment in favor of legal age children is the parent who live with them. Finally, we will consider some of the assumptions in which the expiry of legal age child support payments can occur.

Keywords: Child support payment; Legal age; matrimonial trials.

Recepción original: 21/05/2013

Aceptación original: 22/05/2013 
Sumario: I. Planteamiento preliminar: 1. Régimen anterior a la reforma de 1990; 2. El párrafo segundo del artículo 93 CC según la Ley 11/1990, 15 de junio; 3. Notas sobre alimentos de los hijos y cargas del matrimonio. II. Configuración de la obligación alimenticia de los hijos mayores de edad: 1. Obligación alimenticia como obligación legal; 2 . Obligación alimenticia como obligación mancomunada y divisible de los obligados a prestarla; 3 . Cuantía de la obligación. III. Requisitos para poder reclamar alimentos en favor de los hijos mayores de edad en el procedimiento matrimonial: 1. Convivencia en el domicilio familiar y supuesto de traslado del hijo mayor de edad por razones de estudio; 2. Carencia de ingresos propios: A) Supuesto de haber finalizado los estudios; B) Supuestos de continuación de los estudios; C) Capacidad económica de los progenitores; 3. La carga de la prueba. IV. Extinción de la obligación alimenticia en favor de los hijos mayores de edad: supuestos: 1. Extinción de la pensión en caso de que el hijo no conviva con el progenitor; 2. Extinción de la pensión en el supuesto de que el hijo perciba ingresos; 3 . Extinción de la pensión en el supuesto de que el hijo «ni» estudie «ni» trabaje. V. Conclusiones reflexivas. VI. Bibliografía citada.

\section{PLANTEAMIENTO PRELIMINAR}

\section{Régimen anterior a la reforma de 1990}

Con la redacción inicial del artículo $93^{2}$ CC, se planteó un problema de carácter procesal en relación a los hijos mayores de edad o emancipados, debido a que el precepto aludía únicamente a los hijos menores de edad. En este sentido, conviene precisar que con anterioridad a la introducción del párrafo segundo del artículo 93 CC (regulador de las medidas a adoptar con respecto de los hijos en las sentencias de nulidad, separación o divorcio, por Ley 11/1990, de 15 de octubre, sobre reforma del Código civil, en aplicación del principio de no discriminación por razón de sexo) las decisiones tanto de las Audiencias Territoriales, como de las Provinciales atenuaron de forma parcial el rigor de la regulación normativa precedente, al sostener que el mero hecho de alcanzar los hijos la mayoría de edad no suponía la

2 Dice el mencionado precepto: «1. El Juez, en todo caso, determinará la contribución de cada progenitor para satisfacer los alimentos y adoptará las medidas convenientes para asegurar la efectividad y acomodación de las prestaciones a las circunstancias económicas y necesidades de los hijos en cada momento». 
extinción automática de las cargas familiares derivadas de los alimentos debidos a aquéllos por el párrafo primero del precepto.

En este sentido, GonzÁlez CARRASCO apoyándose en la jurisprudencia de dichos órganos judiciales, afirmaba que «el criterio no era uniforme, de modo que existían numerosas decisiones que ajustándose a la literalidad de la legalidad vigente, entendían que, aunque pudieran concurrir los presupuestos que la harían procedente, la prestación de alimentos del artículo 142 CC debían exigirla por sí mismos los descendientes desde el momento en que alcanzaran la mayoría de edad en los procedimientos correspondientes, ajenos a los cauces del proceso matrimonial ${ }^{3}$.

Por su parte, Montero AROCA ${ }^{4}$, aludiendo a la divergencia entre Audiencias e incluso, entre Secciones de una misma Audiencia, distinguía, la doctrina que seguía en sentido estricto el tenor literal de la norma, argumentando que «si se había fijado pensión al hijo menor y después éste adquiría la mayoría, cesaba la obligación del progenitor condenado, el cual podía dejar de pagar la cantidad fijada para alimentos, aunque siempre cabía la posibilidad de que el hijo ya mayor instará su pretensión de alimentos por el cauce del juicio de alimentos provisionales de la Ley de Enjuiciamiento Civil o por el declarativo ordinario correspondiente a su cuantía». A mayor abundamiento, declaraba que «en los procedimientos de nulidad, separación o divorcio de los progenitores no podía fijarse pensión alimenticia a los hijos mayores de edad o emancipados».

Otro sector jurisprudencial, ante la imposibilidad de establecer al progenitor una condena alimenticia a favor de los hijos mayores de edad o emancipados conforme a lo preceptuado por el artículo 93 CC, originó que otras Secciones y Salas acudiesen a «las cargas del matrimonio» de los preceptos 90.1.d) ${ }^{5}$ y $91 \mathrm{CC}$ y, fundamentaran en éstos sus resoluciones.

En suma, con el régimen anterior se admite, de una parte, la solicitud de los alimentos como «cargas» y, de otra, la fijación de los alimentos a los hijos mayores de edad en el proceso declarativo correspondiente, bien a través del juicio de alimentos [arts. 1609 y ss.,

3 «Los alimentos a los hijos mayores de edad en los procesos matrimoniales: doctrina de las Audiencias». AC, núm. 2, 1998, págs. 26 y ss.

4 Los alimentos a los hijos en los procesos matrimoniales. (La aplicación práctica del artículo 93 (C), Tirant lo Blanch, Valencia, 2002, págs. 195 y ss.

5 Se reordenan las letras b) a e) como c) a f), se añade una nueva letra b) y se modifica el antepenúltimo párrafo por el artículo 1.1 y 2 de la Ley 42/2003, de 21 de noviembre, de modificación del Código Civil y de la Ley de Enjuiciamiento Civil en materia de relaciones familiares de los nietos con los abuelos. 
antigua LEC], o recurriendo al declarativo ordinario caso de que el progenitor alimentante hubiese solicitado la extinción mediante la oportuna modificación de medidas, por haber alcanzado el hijo la mayoría de edad -mayoría que comportaba la no necesidad de alimentos- y, en consecuencia, éstos ya no se debían hacer efectivos por el progenitor obligado.

Por tanto y como ahora constataremos, la Ley 11/1990, de 15 de octubre, añadiría un nuevo párrafo al artículo $93 \mathrm{CC}$, ordenando al Juez fijar en la misma resolución los alimentos a los hijos mayores de edad o emancipados que carezcan de ingresos propios, conforme a los artículos 142 y ss., con la finalidad de evitar la duplicidad de procesos y unificar la dispar doctrina de las Audiencias. Se trataría, como afirma la doctrina mayoritaria ${ }^{6}$, de una norma de carácter procesal.

\section{El párrafo segundo del artículo 93 del Código Civil, según la Ley 11/1990, de 15 de octubre}

Como se ha dicho, aunque la Ley 11/1990, de 15 de octubre, introdujo el párrafo segundo del artículo 93 CC con la pretensión de zanjar la cuestión sobre los alimentos de los hijos mayores de edad, lo cierto es que aún persisten ciertas dificultades interpretativas y prácticas. Con todo, la finalidad de este párrafo es que los alimentos de los hijos mayores de edad puedan exigirse de conformidad a lo establecido por los artículos 142 y ss. CC -es decir, el procedimiento matrimonial- 7 .

Por tanto, se realiza una reforma de carácter procesal fundada en una evidencia social donde «la mayoría de edad no va acompañada

6 Vid., Montero Aroca, Los alimentos a los hijos..., op. cit., pág. 197; Martin NÁJERA, Soledad: "Los alimentos de los hijos mayores de edad en los procesos matrimoniales: El artículo 93.2 y la legitimación», $A C$, núm. 3, 1997, pág. 687; GonZÁLEZ CARRASCO, op. cit., pág. 26.

7 En este sentido, las SSAAPP de Oviedo, de 25 de julio de 1992 y de Ávila, de 8 de septiembre de 1995 (AC: 1995/2445), ponen de manifiesto, que «a partir de la reforma, los alimentos de los juicios matrimoniales dejan de ser únicamente los debidos a los menores para ser los de todos en general, estén o no bajo la potestad de sus padres, siempre y cuando los mayores o emancipados convivan en el domicilio conyugal y carezcan de ingresos propios, si bien mantiene la diferencia entre los debidos al amparo del párrafo primero del artículo 93, en relación con el artículo 154 y los del párrafo segundo del artículo 93, en relación con los artículos 142 y ss., CC». Vid., en doctrina, LÁzARo PALAU, Carmen María: La pensión alimenticia de los hijos. Supuestos de separación y divorcio, Thompson Aranzadi, Navarra, 2008, págs. 32-33. 
de una independencia ni de domicilio familiar ni economía» ${ }^{8}$, por lo que inevitablemente el sentido del recurso al juicio de alimentos, conforme al régimen anterior, pierde su sentido en la medida en que el hijo desde el punto de vista, tanto personal como económico, sigue en el domicilio familiar.

Así, Rivero HERnÁNDEZ, manifiesta que «el nuevo párrafo del artículo 93 tiene una trascendencia eminentemente procesal, en cuanto que permite una acumulación de pretensiones -la de alimentos del hijo mayor de edad a la principal de los cónyuges- en el proceso matrimonial, que se justifica en los principios de economía procesal y de eficacia y, es útil porque aclara definitivamente algunas dudas»9.

Por el contrario, RuIz-Rico Ruiz-Morón, establece que «desde el punto de vista civil, para el legislador español, las necesidades de los hijos mayores de edad o emancipados que carecen de recursos y conviven en el hogar familiar, es una de las cargas familiares en la que han de contribuir ambos padres aunque sea de distinta forma; de la misma manera que también lo tienen que hacer respecto de los hijos menores de edad, sólo que, en relación a estos últimos, no se exige nada más que su propia minoría de edad. Tal equiparación o paralelismo es lo que ha venido a consagrar la reforma, como única vía de incluir, en un proceso en que las partes son los cónyuges, los alimentos en beneficio último de personas distintas y plenamente capaces ${ }^{10}$.

Por lo que a la petición de alimentos se refiere, su solicitud dentro del procedimiento matrimonial, requiere de la concurrencia de los dos requisitos previstos en el precepto. Exigencia que pretende favorecer a los hijos mayores que mantienen la convivencia en el hogar familiar afectado por la crisis.

En este sentido, Guilarte Gutiérrez, dice que «él pensaba al igual que otros autores que el precepto iba teleológicamente encaminado en exclusiva a proteger directamente a dichos hijos organizando el tránsito de la reclamación alimenticia desde la menor a la mayor edad. Por tanto, la razón de dicha inclusión aunque pudiera parecer en principio que tiene como finalidad favorecer al "hijo mayor de edad" -conforme a su referencia normativa-, en realidad se

8 Marín García De Leonardo, María Teresa: Régimen jurídico de alimentos de hijos mayores de edad (estudio del art. 93.2 del Cc.), Universitat de València, 1999, pág. 95.

9 Matrimonio y divorcio. Comentarios al Título IV del Libro Primero del Código civil, (coord.), José Luis Lacruz BerdeJo, Civitas, Madrid, 1994, pág. 1066.

10 "La fijación de alimentos a hijos mayores de edad o emancipados al amparo del párrafo segundo del artículo 93 CC», $A C$, núm. 1, 1993, pág. 1948. 
debe a los perjuicios que la situación anterior ocasionaba al cónyuge que seguía manteniendo económicamente a los hijos» ${ }^{11}$.

En este punto, Marín GARcía dE LEONARdo, matiza que «si estos hijos mayores de edad conviven en el domicilio familiar es de justicia que el progenitor conviviente sea el que reclame lo previsto en el párrafo segundo del artículo $93 \mathrm{CC}$, y reciba la cantidad que se asigne para atender las necesidades del hijo, que aquél no ha dejado de cumplir en ningún momento y que, por otra parte, está legitimado en la medida en que se trata de uno de los efectos que se producen como consecuencia de la nulidad, separación o divorcio». Y, añade que «la consecuencia será que por definición el hipotético alimentista tiene cubiertas sus necesidades esenciales -convive con su progenitor- y es éste quien se vería desamparado si en el procedimiento de crisis no puede actuar la reclamación contra el otro cónyuge para recabar lo que éste ha de aportar» ${ }^{12}$.

En síntesis, la introducción de este segundo párrafo -en favor del progenitor conviviente-, se justifica en los numerosos supuestos que se plantean en relación a la convivencia del hijo mayor de edad con uno de sus progenitores, debido a que el progenitor desde el mismo instante de la separación, permanece con los hijos cubriendo sus necesidades y, por tanto, se trata de una obligación mancomunada. Situación de convivencia que origina, inevitablemente, una obligación al cónyuge no conviviente, consistente en su contribución económica -que tiene una funcionalidad marcada por la Ley-, con la finalidad de paliar las necesidades de los hijos.

Por otra parte, la divergencia interpretativa de las Audiencias Provinciales, que defienden la posibilidad -desde el punto de vista de que el hijo mayor de edad o emancipado es el titular del derecho de alimentos- de que, como titular, el CC lo legitime para intervenir en

11 «A vueltas con los alimentos de los hijos mayores de edad en la crisis matrimonial de sus progenitores: el artículo 93 párrafo segundo del Código Civil», $\operatorname{ArC}$, núm. 3, 1997, pág. 179. En jurisprudencia, la SAP de Barcelona, Sección 12. a de 14 de abril de 1998, defiende que este cónyuge debería ser el destinatario sustantivo de los favores de la norma y, por ende, quien de «iure propio» aparezca legitimado para su reclamación. Puesto que de ésta se desprende que «el titular de la prestación del artículo 93.2 es el cónyuge a cuyo cargo convive el hijo mayor de edad, pues si bien el beneficiario es el hijo, el cónyuge conviviente es quien se hace acreedor de la recepción de la prestación frente al otro cónyuge en la medida en que está contribuyendo en exclusiva al mantenimiento del hijo común por lo que resulta acreedor parcial en la parte que al no conviviente le correspondiere contribuir al sustento del hijo, de suerte que tal prestación alimenticia del artículo 93 tiene su origen en su previa existencia durante la normal convivencia matrimonial, así como en la producción de la crisis conyugal de los progenitores [...]» (AC: 1998/821).

12 Régimen jurídico de alimentos..., op. cit., pág. 97. 
el proceso matrimonial en defensa de su propio derecho, se justifica en su necesaria presencia, con la finalidad, de evitar la posible indefensión derivada en caso de que, sin ser oído el hijo, se discutieran pretensiones que le afectarán solo a él ${ }^{13}$.

Otra cuestión se centra en determinar quién ha de ser parte en los procedimientos matrimoniales, debido a que el párrafo segundo del artículo $93 \mathrm{CC}$ reconoce la posibilidad de reclamarlos en este proceso, pero no aclara la legitimación procesal para ello ${ }^{14}$. Esta cuestión que ha sido objeto de controversias interpretativas doctrinales y jurisprudenciales, ha sido aclarada por la Sentencia del Tribunal Supremo, Sala de lo Civil, de 24 de abril de 2000, dictada en recurso extraordinario en interés de ley y por ello vinculante para los órganos judiciales inferiores, al descartar la legitimación de los hijos mayores, aún cuando en los procedimientos de crisis se soliciten alimentos a su favor por encontrarse conviviendo en el domicilio familiar y carezcan de ingresos propios. Esta sentencia reconoce de forma expresa que «será el progenitor conviviente el legitimado para demandar del otro progenitor su contribución a esos alimentos de los hijos mayores» ${ }^{15}$.

Con este pronunciamiento, el TS ofrece una interpretación del párrafo segundo del artículo $93 \mathrm{CC}$ que, por su carácter vinculante, soluciona la cuestión de la legitimación para reclamar los alimentos en el proceso matrimonial, unificándose los criterios de la jurisprudencia menor ${ }^{16}$.

Legitimación que presupone necesariamente de la concurrencia de los requisitos previstos por el párrafo segundo del artículo $93 \mathrm{CC}$, es decir, que el hijo mayor carezca de recursos suficientes y conviva con el progenitor legitimado, debido a que la ausencia de cualquiera de dichos requisitos comportará la privación al progenitor de la legitimación activa ${ }^{17}$.

13 En este sentido, Vid., las aportaciones de González del Pozo, Juan Pablo: «Problemas procesales planteados por el nuevo párrafo $2{ }^{\circ}$ del artículo 93 del Código Civil», $A C$, núm. 1, 1991, págs. 169 y ss.; MARÍN GARCÍA DE LEONARDO, Régimen jurídico de alimentos..., op. cit., pág. 94.

14 Vid., en esta materia las argumentaciones de Terradez Murillo, Carmen: «Las pensiones alimenticias de los hijos mayores de edad: legitimación para su reclamación», Revista general de derecho, Vol. 56, núm. 675, 2000, pp. 14505-14517.

15 (RJ: 2000/3378).

16 En este sentido, las SSAAPP de Madrid, de 29 de mayo de 2006; de Valencia, de 19 de septiembre de 2005 y, de 23 de mayo de 2006, declaran que quien ostenta la legitimación para reclamar los alimentos es el progenitor conviviente.

17 Vid., SSAAPP de Castellón, de 6 de febrero de 2006 y, de Albacete de 8 de mayo de 2006. 
Por tanto, esta cuestión queda aclarada por el TS al reconocer de forma expresa la legitimación al cónyuge con el que conviven los hijos mayores de edad para demandar del otro su contribución a los alimentos. Así, el TS ha establecido que "el único legitimado para reclamar la pensión es el cónyuge con quien los hijos mayores conviven y quien, por tanto, la cobraría, dispondría y administraría con la obligación de invertir su importe en sus necesidades alimenticias». En la actualidad, con esta sentencia se unifica doctrina, siendo los pronunciamientos posteriores a ésta uniformes al reconocer tal legitimación.

\section{Notas sobre alimentos de los hijos y cargas del matrimonio}

Por cuanto atañe a los supuestos de crisis matrimonial, la posición más defendida por nuestros tribunales sigue siendo la apreciación de los alimentos de los hijos mayores de edad incluidos entre las «cargas del matrimonio».

Si bien, el párrafo segundo del artículo $93 \mathrm{CC}$, prevé que aunque los hijos sean mayores de edad, éstos tendrán derecho a la percepción de alimentos y, por tanto, en la resolución en la que se determine la contribución de cada progenitor para satisfacerlos se podrá ampliar a los hijos mayores de edad en quienes concurran los requisitos previstos por el precepto. De ahí, que se pueda ejercitar la acción en el proceso matrimonial, puesto que las prestaciones de estos hijos -mientras convivan con su progenitor, sin independencia económica- seguirán teniendo la consideración de «cargas del matrimonio».

En particular, la Sentencia del Tribunal Supremo, Sala de lo Civil, de 24 de abril de 2000, declaró que «no puede olvidarse que la posibilidad que establece el párrafo segundo del artículo 93 CC de adoptar en la sentencia que recaiga en estos procedimientos matrimoniales, medidas atinentes a los alimentos de los hijos mayores de edad se fundamenta, no en el indudable derecho de esos hijos a exigirlos de sus padres, sino en la situación de convivencia en que se hallan respecto a uno de los progenitores, convivencia que no puede entenderse como el simple hecho de morar en la misma vivienda, sino que se trata de una convivencia familiar en el más estricto sentido del término con lo que la misma comporta entre las personas que la integran ${ }^{18}$.

\footnotetext{
18 (RJ: 2000/3378).
} 
Otro sector doctrinal ${ }^{19}$, sostiene que dos son los argumentos por lo que no es correcto conceder a los hijos mayores de edad alimentos en el proceso matrimonial a través del recurso a las «cargas del matrimonio». De una parte, porque el párrafo segundo del artículo 93 CC, utiliza unívocamente el vocablo «alimentos», término distinto al de la fijación de la «contribución de cada cónyuge a las cargas del matrimonio» a las que hace alusión el artículo 103.3 CC -referido a las medidas provisionales-; De otra, porque el artículo 90.1.d), al regular los efectos comunes de la nulidad, separación y divorcio, hace nuevamente mención a la contribución de las cargas del matrimonio y alimentos, pero en este precepto la referencia se encuentra localizada en la patria potestad -es decir, a menores de edad-, por lo que está referida a las obligaciones asumidas constante matrimonio.

Por otra parte, en los supuestos de divorcio o nulidad no se puede hacer referencia al concepto de «cargas del matrimonio» del artículo 91.1.d) CC porque o ya no existe el matrimonio o, no ha existido nunca. Así, VALLADARES RASCón, señala que «en la nulidad y el divorcio difícilmente se puede hablar de cargas del matrimonio, si no hay matrimonio $»^{20}$. De esta manera, DE MARINO manifiesta que «sólo una interpretación extensiva de este concepto de cargas, identificándola con el de cargas familiares, permitiría aplicárselo $»^{21}$. Argumentación difícil de mantener, debido a que el precepto alude a las cargas del matrimonio y no a las cargas familiares y, en estos supuestos de divorcio o nulidad, el matrimonio es inexistente.

En virtud de lo anterior, la solución, posiblemente, radicaría en haber utilizado por el párrafo segundo del artículo $93 \mathrm{CC}$ el concepto de cargas de los artículos 90.1.d) y 103 CC, en lugar del de alimentos. Solución que -en términos aplicativos- supondría sustituir la expresión de alimentos por el de cargas, debido a que es mucho más amplio y subsiste con los hijos aunque el matrimonio se haya anulado o disuelto, además el progenitor conviviente sería el titular y, como parte en el proceso, se encontraría legitimado para reclamar la contribución.

19 Vid., LóPEZ-MuÑIZ GoÑI, Miguel: El procedimiento contencioso de separación y

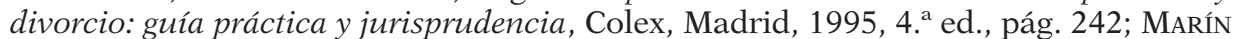
GARCía de LEONARDO, Régimen jurídico de alimentos..., op. cit., pág. 89.

20 Nulidad, separación, divorcio. Comentarios a la Ley de reforma del matrimonio, Civitas, Madrid, 1982, 2. ${ }^{\text {a }}$ ed., pág. 413.

21 «La fijación de alimentos para hijos emancipados en los procesos matrimoniales (y II)», $A C$, núm. 3, 1992, pág. 583. 
Por su parte, aunque el CC considera los alimentos de los hijos como «cargas del matrimonio» a partir de la situación de convivencia, lo cierto es que de la resolución de diversas sentencias se desprende que, a partir de la declaración judicial de divorcio o nulidad no existirán las cargas matrimoniales en este sentido, al desaparecer las obligaciones de los que contrajeron matrimonio entre sí con respecto del grupo familiar y, por tanto, no se pueden establecer contribuciones para el sostenimiento de las cargas familiares, ya que la base de éstas se encuentra en la situación matrimonial de convivencia. Convivencia configurada como la clave de la forma en que la Ley establece que se ha de satisfacer dicha contribución, pero no la obligación.

En este sentido, MARTín NÁJERA, añade que «cuando se produce una situación de crisis matrimonial el núcleo familiar se rompe; los dos obligados conforme al artículo 143 CC ya no conviven con el hijo mayor de edad. No es viable la forma expuesta para las situaciones de convivencia de los dos progenitores, pero cuando uno de ellos sí mantiene esa convivencia, se produce una situación, de hecho, de continuación en la prestación de alimentos. Si la sentencia está llamada a regular la situación que se produce cuando se rompe la convivencia, tanto en las relaciones personales, como en las patrimoniales, ésta debería contemplar también los efectos respecto de los hijos mayores» ${ }^{22}$.

Por lo que a los supuestos de sentencia de separación se refiere, conviene matizar que aunque sigue habiendo matrimonio, lo cierto es que no hay convivencia y, por tanto, no se debe referir a las posibles necesidades de la familia, debido a su disgregación. Por ello, en estos casos, el recurso a las cargas matrimoniales -término empleado en aquellas sentencias que siguieron esta línea con anterioridad a la reforma e incluso con posterioridad-constituye una evasiva, ya que en realidad lo que se deben fijar son los alimentos de los hijos que se derivan de la relación de filiación y no de la situación matrimonial $^{23}$. De ahí, que cuando en la sentencia estas cargas del matrimonio se incluyan como una prestación global por parte del progenitor no conviviente, al elevar a definitivas las medidas provisionales adoptadas, se planteen innumerables controversias.

MARín GaRcía DE LEONARdo dice que «ello no significa que se haya producido la extinción de la familia, sino que a partir de la se-

22 Op. cit., pág. 686.

23 Vid., Marín García de Leonardo, Régimen jurídico de alimentos..., op. cit., pág. 82; Veiga Nicole, Elisa: «La pensión de alimentos en la Ley 30/1981, de 7 de julio», en Problemas candentes en los procesos de familia, Madrid, 1995, pág. 128. 
paración ha surgido una unidad familiar distinta, con una serie de necesidades que no se pueden englobar en lo que jurídicamente se conceptúa como cargas matrimoniales» ${ }^{24}$.

En suma, no se niega la existencia de la obligación, sino la consideración de ésta como carga matrimonial.

En particular y, por lo que a esta materia se refiere, la Sentencia de la Audiencia Provincial de Madrid, Sección 22. ${ }^{a}$, de 25 de septiembre de 1995, dispuso que «las cargas del matrimonio no dejan de ser un concepto residual y referible estrictamente a las cargas del sistema económico matrimonial (pago de préstamos y créditos de la sociedad ganancial), y que los alimentos de los hijos han de establecerse en su más amplio sentido que se contiene en el artículo 142 CC, comprendiendo por tanto, todo lo indispensable para el sustento, habitación, vestido, asistencia médica, educación e instrucción ${ }^{25}$.

Así, PÉREz MARTín, señala que «deberán incluirse aquellas obligaciones frente a terceros que, contraídas por el matrimonio mientras vivían unidos, han de seguir afrontándose hasta su total extinción a pesar de la ruptura de la convivencia; por ejemplo, los créditos personales e hipotecarios [...]» ${ }^{26}$. Y, VEIGA Nicole, añade que «dado el carácter residual que el concepto de cargas del matrimonio tiene en las sentencias de nulidad, separación o divorcio, no puede incluirse en tal concepto la pensión alimenticia que puede corresponder a los hijos» ${ }^{27}$.

En definitiva, los alimentos de los hijos mayores de edad en las sentencias de separación o divorcio, no se deben configurar como cargas derivadas de una situación familiar, debido a que son concebidas como un concepto residual-referido únicamente a las cargas del sistema económico matrimonial-, mientras que los alimentos de los hijos encuentran su regulación en los artículos 142 y ss., CC-comprendiendo todo lo indispensable para el sustento, habitación, vestido, educación, asistencia médica e instrucción ${ }^{28}$.

24 Régimen jurídico de alimentos..., op. cit., pág. 83. Y, GUILARTE GUTIÉRREZ, sostiene que «acepta el término cargas matrimoniales desde una perspectiva, proponiendo para evitar confusiones cambiarlo por el término cargas familiares» (op. cit., págs. 20 y ss.).

25 (AC: 1995/2220).

26 El procedimiento contencioso de separación y divorcio: comentarios, texto legal, casos prácticos, jurisprudencia y formularios de Derecho de familia, T. IV, Lex Nova, Valladolid, 1999, 3. . ed., pág. 455.

27 Op. cit., págs. 133-134.

28 En este sentido, PÉrez MArTín, Antonio Javier, dice que «esta línea se va imponiendo cada vez con más fuerza en los Tribunales, conscientes de los problemas que supone trasplantar el concepto de cargas del matrimonio del artículo 103. 3 CC a la sentencia, entendiendo que al dictarse la sentencia de separación no está permitida ya tal generalización globalizada, exigiéndose, por el contrario, una clara indivi- 


\section{CONFIGURACIÓN DE LA OBLIGACIÓN ALIMENTICIA DE LOS HIJOS MAYORES DE EDAD}

El párrafo segundo del artículo 93 CC alude a una obligación alimenticia en sentido estricto, de ahí su remisión a los artículos 142 y ss., de forma que aún a pesar de que el precepto utiliza erróneamente el término "fijará los alimentos», no cabe entender que se trate de algo que se deba hacer «en todo caso» ${ }^{29}$.

Asimismo, la regulación de estos alimentos por el párrafo segundo del artículo 93 CC, ha originado cierta confusión material, debido a la posibilidad de entender que éstos son distintos a los «alimentos entre parientes ${ }^{30}$. En este sentido, la jurisprudencia menor ha sido prácticamente unánime al afirmar, acertadamente, que «los alimentos a los hijos mayores de edad no se rigen por el artículo $154 \mathrm{CC}$, sino por el artículo $142 \mathrm{y}$, de ahí que se limiten a lo indispensable para la subsistencia. Configurándose el párrafo segundo del

dualización y desglose» (La ejecución de las resoluciones dictadas en procedimientos matrimoniales: comentarios, texto legal, casos prácticos, jurisprudencia y formularios de Derecho de familia, T. IV, Lex Nova, Valladolid, 1997, 3. ${ }^{\text {a }}$ ed., págs. 453 y ss.). También, MARín GARCía DE LEONARDO, afirma que «en el ámbito de las prestaciones económicas a acordar entre los cónyuges en el cauce procesal de separación o divorcio, debe distinguirse, a tenor de su regulación legal, aquéllas que deben mantener su vigencia en tanto no exista sentencia firme y definitiva, a adoptar en la pieza de medidas provisionales, que se engloban bajo el concepto de cargas matrimoniales en el que quedará comprendida cualquier obligación tanto de los propios cónyuges, como respecto de los hijos, porque está todavía pendiente establecer o no la separación y, por otra parte, aquéllas que han de regir a partir de la sentencia definitiva estimatoria a dictar en la litis principal, puesto que éstas sustituyen a las anteriores y el Código civil ya no las contempla con la generalización globalizadora, distinguiendo entre aquéllas que tienen por beneficiarios a los hijos, bajo la cobertura legal de alimentos [art. $93 \mathrm{CC}$ ], y aquéllas cuyo destinatario es uno de los progenitores» (Régimen jurídico de alimentos..., op. cit., pág. 85).

29 Vid., en este sentido, MonTERo Aroca, Los alimentos a los hijos..., op. cit., pág. 17.

30 Respecto de la obligación de alimentos entre parientes, vid., por todos, LASarte Álvarez, Carlos: Derecho de Familia. Principios de Derecho Civil, T. IV, Marcial Pons, Madrid, 2012, 11. ${ }^{a}$ ed., págs. 342-354, así como JiménEz MuÑoz, Francisco Javier: «La regulación española de la obligación legal de alimentos entre parientes», Anuario de Derecho Civil, T. LIX-II, abril-junio, 2006, págs. 743-792 y, «La obligación legal de alimentos entre parientes en España», en Perspectivas del Derecho de Familia en el siglo XXI (XII Congreso Internacional de Derecho de Familia. Conferencias, ponencias e informes publicados), Carlos LASARTE Álvarez (Dir.), UNED/IDADFE, Sevilla, 2004, p. 152; LóPEz Peláez, Patricia: «La financiación de la calidad de vida de las personas mayores renta vitalicia y contrato de alimentos», RMTAS, págs. 107-133 $\mathrm{y}$, "El contrato de vitalicio la cesión de un inmueble a cambio de alimentos», Consultor inmobiliario, 52, 2004, págs. 3-39; MondÉJAR PeÑA, M. ${ }^{a}$ Isabel: «La obligación de alimentos y las políticas de la administración española sobre la protección de los mayores y dependientes», Revista jurídica Universidad Autónoma de Madrid, 14, 2006, págs. 128-185. 
artículo $93 \mathrm{CC}$ como una norma procesal y, no como una norma

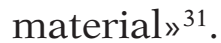

Por otra parte, la reducción de los alimentos de los hijos mayores de edad a los «indispensables», se justifica en que "el párrafo segundo del artículo 93 CC parte de que las obligaciones propias de la patria potestad se han extinguido por la mayoría de edad o emancipación del hijo y, centra entonces la obligación, no tanto en la relación paterno-filial, cuando en la más general de los alimentos entre parientes» ${ }^{32}$.

Por tanto, ésta obligación alimenticia, se concibe como una obligación en sentido estricto, ya que su contenido se encuentra limitado solo a lo establecido de modo taxativo por los artículos 142 y ss., CC-al exigir la existencia de distintos requisitos-.

En lo que a esta materia se refiere, la Sentencia de la Audiencia Provincial de Barcelona, Sección 12. ${ }^{a}$, de 25 de mayo de 1998, señaló que: «a diferencia de la prestación alimenticia a favor de los hijos menores de edad, que es apreciable de oficio, cuando se trata de hijos mayores de edad, rige el principio dispositivo y de rogación $[\ldots]{ }^{33}$.

De modo que en los supuestos de hijos mayores de edad -si se dan los requisitos previstos por el CC en los artículos 142 y ss.- ambos progenitores tendrán la obligación de prestarles los alimentos -en cantidad proporcional a su caudal y en función de la necesidad del alimentista-. De ahí, que el artículo 142, prevea que por alimentos se entiende: «Todo lo que es indispensable para el sustento, habitación, vestido y asistencia médica», siempre que el hijo "no haya terminado su formación por causa que no le sea imputable», lo que comporta la permanencia de la obligación alimenticia mientras subsista la necesidad del hijo, no pudiendo ser entendida como una obligación incondicionada, ya que dependerá de los requisitos previstos en el párrafo segundo del artículo 93.

31 SAP de Asturias, de 23 de febrero de 1999 (AC: 1999/3358). También, en los mismos términos, la SAP de Barcelona, de 31 de marzo de 2000, señaló que: «la causa jurídica de la prestación no se encuentra en los deberes inherentes a la patria potestad, sino en el deber general de alimentos entre parientes que se recoge en los artículos 142 y ss. CC» (AC: 2000/4575). Por el contrario, la SAP de Badajoz, de 23 de septiembre de 1998, habla de «institución específica» (AC: 1998/1738). En doctrina, vid., las aportaciones de LázARo PALAU, op. cit., págs. 29-30.

32 Montero Aroca, Juan: Los procesos matrimoniales: comentarios a la Ley 30/1981, de 7 de julio, sobre los procedimientos en las causas de nulidad, separación y divorcio (comentarios, jurisprudencia y formularios), Tratados y Manuales, Tirant lo Blanch, Valencia, 1997, pág. 465.

33 (AC: 1998/5430) y, vid., en el mismo sentido, entre otras, la SAP de Valencia, de 26 de enero de 2000 (AC: 2000/4067). 
De lo anterior, conviene precisar que esta obligación presenta un régimen distinto al de los hijos menores de edad. De una parte, porque no es incondicional y para su concesión es necesario acreditar la necesidad de los alimentos -sin que exista ninguna presunción legal de dicha necesidad-; De otra, porque puede tener un contenido menor que el de los hijos menores, pudiéndose incluso reducir al mínimo imprescindible o, extinguirse y, finalmente, porque estos alimentos no gozan de preferencia frente a otros parientes por lo que se ven afectados por las limitaciones propias del régimen legal de «alimentos entre parientes» $\mathrm{y}$, por tanto, deberán ser siempre proporcionales al caudal y medios del alimentante y, a las necesidades del alimentista.

En definitiva, esta obligación aunque se podrá prestar a elección del alimentante -ya pagando la pensión fijada, ya manteniendo en su casa al que tiene el derecho a ello-, lo cierto es que este "derecho de opción» no será un derecho absoluto, ya que dependerá de la situación de convivencia en el domicilio o de independencia en la que se encuentren y, de las circunstancias concretas del caso ${ }^{34}$. Además es configurada en el CC como una obligación legal y, al recaer sobre ambos progenitores, como una obligación mancomunada y divisible.

\section{Obligación alimenticia como obligación legal}

Por cuanto atañe a la obligación alimenticia a los hijos mayores de edad, conviene precisar que aunque se constituye como una obligación legal que se impone a personas determinadas, como una consecuencia derivada de la vinculación existente del alimentante con el beneficiario -ya por vínculos de parentesco o ya de estado-, lo cierto es que consiste en el pago de una pensión periódica, con la finalidad de cubrir las necesidades de los hijos y, presenta un carácter más restrictivo que la de los menores de edad, debido a la exigencia de una serie de requisitos para su nacimiento [arts. 142 y ss., CC], por lo que debe subsistir a favor del hijo aún después de su mayoría de

\footnotetext{
34 En este sentido, Pérez Martín, Antonio Javier, sostiene que «la facultad de opción del artículo 149 CC no es tan absoluta que impida apreciar casos en que, por oponerse este derecho al ejercicio de otro preferente, puedan existir causas justificadas de orden moral que se opongan a que el alimentista se traslade al domicilio del alimentante. La falta de contacto entre ambos, la enemistad manifiesta [...], son supuestos en los que el derecho de opción debe ser objeto de valoración judicial» ( $\mathrm{La}$ modificación y extinción de las medidas. Aspectos sustantivos y procesales, en Tratado de Derecho de Familia, T. IV, Lex Nova, Valladolid, 2007, pág. 603).
} 
edad -siempre que permanezca en situación de necesidad por causa que no le sea imputable-.

Por otra parte, esta obligación que participa de las notas de solidaridad, no compensación, irrenunciabilidad e, intransmisibilidad, encuentra su fundamento en el contenido del artículo 39. $2 \mathrm{CE}$, al establecer que «los padres deben prestar asistencia de todo orden a los hijos habidos dentro o fuera del matrimonio, durante su minoría de edad y en los demás casos en que legalmente proceda», lo que nos remite a lo previsto por los artículos 142 y ss., CC -referentes a la regulación de alimentos entre parientes-.

En síntesis, la norma constitucional hace una distinción entre minoría y mayoría de edad y, señala que en la mayoría de edad la obligación de los padres como derivada de la patria potestad cesa, salvo casos excepcionales ${ }^{35}$.

Por su parte, la jurisprudencia menor, la concibe como «el deber impuesto a una o varias personas de asegurar la subsistencia de otra o de otras y supone la conjunción de dos partes, una acreedora, que tiene derecho a exigir y recibir los alimentos, y la otra, deudora, que tiene el deber moral y legal de prestarlos, con la particularidad de que el primero ha de reunir hipotéticamente la condición de necesitado y el segundo poseer medios y bienes aptos para atender la deuda». Y respecto a la catalogación de la obligación alimenticia, han señalado que "ésta se encuentra catalogada desde antaño [STS, de 20 octubre 1924], como personalísima, irrenunciable e indeterminada en cuanto al tiempo, y que comprende los gastos indispensables para el sustento, habitación, vestido, asistencia médica, así como educación e instrucción del alimentista mientras sea menor y aún después cuando no haya terminado su formación por causa que no le sea imputable [art. $142 \mathrm{CC}]{ }^{36}$.

En suma, tres son los requisitos exigidos por Ley para que la obligación de alimentos entre parientes tenga lugar. De una parte, la existencia de un vínculo de parentesco entre el alimentista y el alimentante -es decir, entre el hijo mayor de edad y el obligado a prestarla [art. $143 \mathrm{CC}$ ]-; De otra, la existencia de una situación de necesidad por parte del hijo que los reclama, debiendo tenerse en

35 A esta conclusión llega MARín GaRcía DE LEONARDo, Teresa, apoyándose en la SAP de Barcelona, de 31 de julio de 1997, al disponer que «el deber de alimentos nace por ministerio de la norma, correspondiendo a los padres aunque no tengan la patria potestad y nunca se dispensa» ( «La temporalidad de los alimentos de los hijos mayores de edad», Sepin Familia, 2003, pág. 25)

36 SAP de Barcelona, Sección 12. ${ }^{a}$, de 14 de abril de 1998 (AC: 1998/821). 
cuenta que comprenderá la educación e instrucción, siempre que éste no haya finalizado su formación por causa que no le sea imputable y que dicha necesidad no provenga de su falta de aplicación al trabajo o de su mala fe y, finalmente, que el obligado tenga medios económicos para satisfacer la deuda.

Por cuanto atañe al primer requisito, conviene precisar que, indudablemente, entre los sujetos obligados a prestarse los alimentos legales están los padres respecto de los hijos y, viceversa, como ascendientes y descendientes de grado más próximo [art. $144 \mathrm{CC}$ ] con independencia de que el hijo beneficiario alcance la mayoría de edad ${ }^{37}$. También la jurisprudencia menor ${ }^{38}$ se ha pronunciado en idéntico sentido, al sostener que la mayoría de edad del alimentista no lleva aparejada de forma automática, la pérdida del derecho de la pensión alimenticia, sino que es la emancipación -entendida como vida independiente- la que provoca el cese del deber paterno de velar y tutelar a sus hijos y la que origina el nacimiento de la obligación legal de alimentos -si éste se encuentra en una situación de necesidad-y, por tanto, será la emancipación la que hará surgir el derecho y deber de alimentar al hijo, como una prestación legal autónoma, al darse esa situación de necesidad.

Por lo que a los otros dos requisitos se refiere, conviene matizar que éstos se presentan como presupuestos de carácter objetivo, ya que tendrán lugar respecto del caso concreto de que se trate, quedando su determinación sujeta al buen arbitrio del Juez, quien deberá tener en cuenta la capacidad económica de los progenitores a prestarlos, en el entendido de que si esta capacidad es escasa -hasta el punto de no poder satisfacerlos sin desatender sus propias necesidades y las de su familia-, el CC prevé la cesación de la obligación de prestar los alimentos [art. 152.2 CC].

Respecto al requisito del «estado de necesidad del hijo», conviene decir que se constituye como el requisito principal e inicial de la obligación -ya que determina el nacimiento de ésta, además de comportar su exigibilidad [art. $148 \mathrm{CC}$ ], debido a que el fundamento primordial de la obligación radica en proteger la vida del pariente necesitado -es decir, del hijo mayor de edad o emancipado-. Por

37 Vid., Aguilar Ruiz, Leonor: «El derecho a recibir alimentos de los hijos mayores de edad que voluntariamente abandonan el domicilio familiar. Comentario a la STS de 23 de febrero de 2000», Derecho Patrimonial, núm. 6, 2001, pág. 329.

38 Vid., las SSAAPP de Gerona, de 28 de febrero de 1991 (RJ: 1991/726); de Barcelona, de 2 de julio de 1991 (RJ: 1991/83); de Zaragoza, de 3 de noviembre de 1992 (AC: 1992/1567). 
tanto, su nacimiento tendrá lugar cuando éste se encuentre en dicha situación -la cual no se presume, sino que será necesario acreditar-.

Asimismo, este requisito de forma conjunta con el de «capacidad económica del obligado» a prestarlos, determina la cuantía de los alimentos, al desprenderse del artículo 146 CC, que «la cuantía de los alimentos será proporcionada al caudal o medios de quien los da y a las necesidades de quien los recibe». De ahí, que el artículo 147 prevea que «los alimentos, en los casos a que se refiere el artículo anterior, se reducirán o aumentarán proporcionalmente según el aumento o disminución que sufran las necesidades del alimentista y la fortuna del que hubiere de satisfacerlos». Por tanto, se trata de un estado o situación de necesidad de carácter relativo, debido a que está en función de la condición personal y social del beneficiario y, económica del obligado a prestarla, configurada como un presupuesto final, cuya pretensión es determinar la duración de dicha obligación. Obligación que cesará cuando se den los requisitos previstos por el artículo 152. $3 \mathrm{CC}^{39}$.

No obstante, aún a pesar de lo antes descrito, este requisito en los supuestos en los que el alimentista sea mayor de edad con vida independiente, adquiere una especial relevancia, ya que el deber de los padres a prestarle alimentos queda condicionado. Así lo constata, en particular, la Sentencia del Tribunal Supremo, de 23 de febrero de 2000, al sostener que «a que se den determinadas circunstancias como reveses de fortuna, siniestros imprevisibles, enfermedades, imposibilidad para trabajar [...] que comportan la imposibilidad del hijo de seguir manteniéndose por sí mismo y, de otro, a la subsistencia de las necesidades del alimentista» ${ }^{40}$.

En suma, los motivos por los que este estado de necesidad es oportuno que sea valorado y comprobado previamente, son: De una parte, porque creemos necesario que quien lo sufra no se encuentre en condiciones de poder proveer por sí mismo su propio sustento, caso que tendría lugar cuando el hijo mayor de edad dispusiese de recursos propios para satisfacer sus necesidades vitales y, de otra, porque la necesidad de éste no puede ser considerada como un presupuesto legal absolutamente inseparable de la obligación de alimentos, ya que aun existiendo la necesidad, el CC prevé el cese de la obligación alimenticia en aquéllos supuestos en los que «la nece-

39 "Cuando el alimentista pueda ejercer un oficio, profesión o industria, o haya adquirido un destino o mejorado de fortuna, de suerte que no le sea necesaria la pensión alimenticia para su subsistencia».

40 (AC: 2000/1169). 
sidad de aquél provenga de su mala conducta», es decir, cuando sea imputable al hijo mayor de edad ${ }^{41}$ [art. 152. 5 CC].

En definitiva, aunque si concurren los requisitos descritos -al tratarse de una obligación legal- la obligación alimenticia nacerá en dicho momento, lo cierto es que dicha obligación será exigible desde que los necesitase para subsistir la persona que tenga el derecho a percibirlos, pero no se abonarán sino desde la fecha en que se interponga la demanda [párrafo primero del art. 148 CC].

Díez-Picazo y Ponce de León y Gullón Ballesteros acertadamente, sostienen que con este precepto todo apunta a que la pretensión del Legislador posiblemente ha sido única y exclusivamente poner de relieve «la hipótesis de que el alimentista reclamase judicialmente la efectividad del derecho, pero no hace imperativa esta vía. La obligación surge desde que se da la menesterosidad, y puede ser cumplida por el obligado voluntariamente sin necesidad de intervención judicial» ${ }^{42}$.

No obstante, la interpretación del precepto ha dado lugar a una cierta confusión respecto del momento en que nace la obligación alimenticia y, el momento en que ésta se cumple. En este sentido, doctrina y jurisprudencia son unánimes al establecer que «la deuda es preexistente a la decisión judicial, de forma que si el alimentante cumple ante la petición de alimentos por vía extrajudicial y comienza a prestarlos estará llevando a cabo el cumplimiento de una obligación civil» ${ }^{43}$. Además se debe tener presente que la obligación de alimentos respecto de los mayores de edad no cesará si no tienen lugar las causas de extinción [arts. 150 y 152 CC].

Por su parte, BELTRÁN DE HEREDIA y ONís ${ }^{44}$, señala que no hay dos momentos diferentes -uno de nacimiento y otro de cumplimiento de la obligación-, sino que ambos no son siempre coincidentes, debido a que de otra forma habría que considerar que el cumplimiento voluntario -sin interposición de demanda-, no tendría eficacia jurídica. Por tanto, la obligación alimenticia surge como pura desde el momento de la concurrencia de los tres requisitos descritos y, será

\footnotetext{
$41 \quad$ Vid., Aguilar Ruiz, op. cit., pág. 331.

42 Sistema de Derecho Civil, Vol. IV, Tecnos, Madrid, 1990, pág. 53.

43 Vid., Marín García de Leonardo, Régimen jurídico de alimentos..., op. cit., pág. 26; Díez-Picazo y Ponce de León y Gullón Ballesteros, op. cit., pág. 53; Albácar lópez, José luis y Martín Granizo Fernández, Mariano: Código civil. Doctrina y Jurisprudencia, T. I, Trivium, Madrid, 1991, 2. ${ }^{\text {e ed., pág. } 949 .}$

${ }_{4}$ Comentarios al Código civil y Compilaciones Forales, T. III, Vol. II, Edersa, Madrid, 1978, pág. 47.
} 
exigible, desde luego, sin que esté supeditada al acontecimiento posterior de la interposición de la demanda.

En virtud de lo anterior, está justificada la afirmación que sostiene que, esto resultará más evidente en los supuestos de crisis matrimonial, puesto que la obligación no se realizará de forma voluntaria en muchos casos, debido a que como norma general hasta la separación los progenitores no se suelen plantear dejar de atender las necesidades del hijo, mientras éstas subsistan y no provengan de la mala conducta o falta de aplicación del trabajo de éstos ${ }^{45}$.

\section{Obligación alimenticia como obligación mancomunada y divisible de los obligados a prestarla}

Cuando la obligación alimenticia recae sobre dos o más personas, el CC la configura como una obligación mancomunada y divisible, puesto que el párrafo primero del artículo $145 \mathrm{CC}$, establece que «cuando recaiga sobre dos o más personas la obligación de dar alimentos, se repartirá entre ellas el pago de la pensión en cantidad proporcional a su caudal respectivo».

Por ello, MARín García de LEONARDo, afirma que no se tratará de una deuda de carácter solidario, encontrándose este carácter reforzado con el contenido del párrafo segundo del artículo 145 CC, al disponer que «en caso de urgente necesidad y por circunstancias especiales, podrá el Juez obligar a una sola de ellas a que los preste provisionalmente, sin perjuicio de su derecho a reclamar de los demás obligados la parte que les corresponda» ${ }^{46}$.

También, Delgado EchevarRía ${ }^{47}$, respecto de la deuda de carácter no solidario junto a la obligación alimenticia realizada por ambos progenitores, matiza que aunque el artículo 145 CC configura la obligación como mancomunada divisible, lo cierto es que su párrafo primero dice dos cosas distintas. De una parte, que en la relación interna la deuda se divide en proporción al caudal de cada uno de los obligados y, no por mitad o por iguales partes; De otra, aunque el acreedor no se puede dirigir contra uno sólo de ellos para exigir el pago de la totalidad, lo cierto es que esto no se desprende, necesariamente, de la letra de este párrafo, pero sí de la relación con el siguiente, que

45 Vid., Marín García de Leonardo, Régimen jurídico de alimentos..., op. cit., págs. 26 y ss; Díez-PiCAzo y Ponce de León y, Gullón Ballesteros, op. cit., pág. 53.

46 Régimen jurídico de alimentos..., op. cit., pág. 27.

47 Comentario del Código civil, T. I, Ministerio de Justicia, Madrid, 1991, págs. 528 y ss. 
permite imponer a uno sólo de los obligados el pago de la totalidad únicamente en caso de urgente necesidad y por circunstancias específicas. Además, señala que en los demás casos -puesto que el precepto alude a los supuestos en los que los progenitores sean los obligados-, deberán contribuir en cantidad proporcional a sus respectivos caudales, no pudiendo repartirse la deuda en partes iguales y, añade que en los supuestos de urgente necesidad y circunstancias especiales se establece una solidaridad provisional entendida en un doble sentido: De una parte, que quien paga en cumplimiento de una orden judicial puede reclamar a los demás obligados la parte que le corresponda, por tanto, su desembolso no es económicamente definitivo; De otra, que la decisión judicial ha de prevalecer solo durante cierto tiempo.

En suma, del párrafo segundo del artículo 145 CC se desprende que el alimentante no se podrá dirigir contra cualquiera de los obligados para exigirle el pago de la pensión. Sin embargo, el Juez sí podrá, en circunstancias excepcionales, obligar a una de las partes para que los preste de forma provisional, siendo necesario para reclamarlos demandar de forma conjunta a todos y cada uno de los alimentantes obligados, pagando cada uno de ellos únicamente la parte proporcional que le corresponda conforme a su caudal económico.

Por cuanto atañe a los supuestos de crisis familiar, conviene precisar que aunque la solución sigue siendo la misma, lo cierto es que la diferencia para el progenitor conviviente con el hijo mayor de edad radica en su forma de hacerla efectiva, debido a que al deshacerse el núcleo familiar, el hijo pasa de convivir con ambos progenitores a convivir con uno de ellos.

Sin embargo, si el hijo mayor de edad pasara a vivir de forma independiente, sí podrá reclamar los alimentos en el supuesto de necesitarlos a través del juicio de alimentos -demandando a ambos progenitores-. Supuestos en los que el párrafo segundo del artículo 93 CC ofrece una solución al hijo mayor de edad o emancipado que conviva en el domicilio familiar y carezca de ingresos propios.

En este sentido, la doctrina ${ }^{48}$ ha sido unánime al establecer que todo apunta a que la pretensión del Legislador, en este supuesto, posiblemente ha sido tener en cuenta que aunque éstos ya no están sujetos a la patria potestad de los padres, siguen teniendo una dependencia económica de los mismos -ya porque se encuentran dentro de un periodo de formación académica, ya porque, en la actualidad, el mercado laboral presenta ciertas dificultades para acceder al empleo-.

48 Vid., Marín García de Leonardo, Régimen jurídico de alimentos..., op. cit., pág. 23.

(C) UNED. Revista de Derecho UNED, núm. 12, 2013 
Por tanto, si se dan los requisitos previstos por el párrafo segundo del artículo 93 CC, las necesidades alimenticias se seguirán atendiendo por el progenitor conviviente -progenitor que es obligado, de forma mancomunada con el otro, en función a la parte proporcional según su caudal y medios económicos-, con independencia de la solución a adoptar para resolver la crisis matrimonial.

Marín GaRcía de LeONARdo, -con acierto- establece que «el legislador, partiendo de la existencia de la obligación en los casos señalados por el párrafo segundo del artículo 93 CC, determina su efectivo cumplimiento, lo que afecta evidentemente a los que son obligados ${ }^{49}$.

De lo anterior, conviene precisar que se deduce la posibilidad de que uno de los cónyuges solicite dicho cumplimiento, ya que lo que se dirime es la reglamentación interconyugal del cumplimiento de dicha obligación, derivada ésta de la ruptura de la relación matrimonial. En este sentido, esta misma autora, añade que «de otra forma, el progenitor conviviente va a verse perjudicado, porque va a ser absurdo pensar que sólo va atender su parcela de obligación en tanto en cuanto convivan con él los hijos ${ }^{50}$.

Sin embargo, del literal del precepto se desprende que se prevé la posibilidad de fijar por el Juez el cumplimiento y cuantificación de la obligación -que uno de los progenitores está prestando por sí sólo- en el mismo proceso en el que se dirime la nulidad, separación o divorcio, siempre que se cumplan los requisitos previstos en el artículo, debido a que en la actualidad aún a pesar de que los hijos cumplan la mayoría de edad, mantienen como norma general una situación de dependencia económica y de convivencia en el domicilio familiar, pero si bien, no establece los requisitos necesarios para que el hijo sea acreedor de los alimentos ${ }^{51}$. Requisitos determinados conforme a lo previsto en los artículos 142 y ss., CC.

\footnotetext{
49 Régimen jurídico de alimentos..., op. cit., pág. 46.

50 Ibídem.

51 En este sentido, la SAP de Valencia, Sección 8. ${ }^{\text {a }}$, de 26 de enero de 1998, señala que: «La ubicación sistemática del párrafo segundo del artículo 93 CC claramente configura la pensión como medida a adoptar como consecuencia de la separación, nulidad o divorcio, y en el ámbito de dichos procesos y, por esa misma razón, parece lógico deducir que quienes son parte en tales procesos estén legitimados para solicitar la pensión en su estricto ámbito, pareciendo asimismo evidente que la intención del legislador fue la de hacer frente a la realidad social que viene a mostrar que en muchas ocasiones de mayoría de edad no supone, ni mucho menos, la independencia económica, y que el cónyuge con el que quedará el hijo mayor de edad, pero dependiente económicamente, pudiera solicitar lo necesario para el mantenimiento de tal situación» (AC: 1998/44).
} 
En sintesis, para la fijación de la prestación alimenticia a los hijos mayores de edad o emancipados se podrá utilizar, bien el cauce del juicio de alimentos previsto en la LEC - para los supuestos en los que el hijo no conviva en el domicilio familiar y se encuentre en situación de necesidad-, bien el previsto en el párrafo segundo del artículo 93 CC. Párrafo que posibilita que la prestación alimenticia se realice en el procedimiento matrimonial de sus progenitores, siempre que se cumplan los dos presupuestos previstos, teniendo además éste un contenido amplio, conforme a la referencia prevista por aquél en los artículos 142 y ss.

\section{Cuantía de la obligación}

Dice el artículo 146 CC: «la cuantía de los alimentos será proporcionada al caudal o medios de quien los da y a las necesidades de quien los recibe».

Conforme al tenor literal del precepto, se deduce la necesidad de establecer el binomio «medios económicos-necesidad» ${ }^{52}$, debiendo atenderse, de una parte, los medios económicos del progenitor obligado y, de otra, las necesidades que presenta el hijo mayor de edad.

En este sentido, la doctrina es unánime al establecer que el precepto se decanta a la hora de establecer la cantidad o cuantía de la obligación, por la utilización de una regla de proporcionalidad entre el caudal del alimentante y las necesidades del alimentista. Así, MARÍN GARCÍA DE LEONARDO matiza que «está proporcionalidad estará al prudente arbitrio del tribunal sentenciador de instancia» ${ }^{53}$.

Por su parte, del artículo 145 CC se desprende que esta obligación se debe repartir entre ambos progenitores. Aspecto que adquiere una especial relevancia a la hora de establecer la cuantía de ésta. Sin embargo, aunque el precepto dice que ambos progeni-

52 Vid., Marín García de LeOnARdo, Régimen jurídico de alimentos..., op. cit., pág. 191.

53 Régimen jurídico de alimentos..., op. cit., pág. 154. También, VÁzQuEz YruzuBIETA, Carlos: dispone que «la cuantía de los alimentos deberá distribuirse teniendo en cuenta la situación patrimonial de los obligados al momento de dictarse la sentencia» (Régimen jurídico de la celebración y disolución del matrimonio: Ley 30/1981, de 7 de julio, (Monografías), Edersa, Madrid, 1981, pág. 424). Desde el punto de vista jurisprudencial, así se desprende de la SAP de Madrid, Sección 22. ${ }^{\text {a }}$ de 3 de octubre de 1995, al disponer que «lo que el artículo 146 CC tiene en cuenta no es rigurosamente el caudal de bienes de que pueda disponer el alimentante, sino simplemente las necesidades del alimentista puesto en relación con el patrimonio de quien haya de darlos, cuya apreciación de proporcionalidad viene atribuido al prudente arbitrio del Tribunal sentenciador de instancia» (AC: 1995/2101). 
tores deben contribuir a los gastos que comporte el mantenimiento de los hijos, ello no implica la necesaria igualdad de contribución. Contribución que estará en función de las posibilidades que presente cada progenitor, es decir, que si ambos disponen de ingresos económicos, los dos se encontrarán obligados y, por tanto, el pago de la pensión alimenticia, será distribuida entre éstos en proporción a sus caudales respectivos, con la finalidad de dar fiel cumplimiento a las necesidades alimenticias de los hijos, en el sentido previsto por el artículo 142 -es decir, lo indispensable para el sustento, habitación, vestido y asistencia médica, como los gastos que se deriven de la educación e instrucción-y, no para el mantenimiento de un nivel de vida análogo al que la familia tenía constante el matrimonio, ni la de compensar situaciones de desequilibrio económico.

Por otra parte, algunos autores ${ }^{54}$, con la finalidad de evitar una distribución cuantitativamente igualitaria en los supuestos de similitud de ingresos de los progenitores, afirman que a la hora de fijar la cuantía se deberá tener en consideración el trabajo de atención que desempeña el progenitor conviviente con el hijo mayor de edad o emancipado carente de ingresos propios como contribución a sus alimentos, debido a que es valorado como una carga matrimonial y, se encuentra previsto por el artículo $103 \mathrm{CC}$ en las medidas previas a la demanda y a los hijos sujetos a patria potestad.

Desde el punto de vista de la jurisprudencia menor, en particular, la Sentencia de la Audiencia Provincial de Barcelona, Sección 18. ${ }^{a}$, de 12 de mayo de 1999, establece que «la dedicación que realiza el progenitor conviviente con el hijo, también se considera susceptible de ser valorada a la hora de fijar la pensión alimenticia, entendiendo esta dedicación como una satisfacción «en especie» de ésta» y, precisa que «no será válida la sustitución de esta prestación por una transmisión futura hereditaria de un bien del obligado al pago,

54 Vid., Marín García de LeOnardo, Régimen jurídico de alimentos..., op. cit., pág. 155. También DE MARINO, precisa que «la razón de ser es la misma en el supuesto de hijos mayores de edad o emancipados», debido a que el artículo 4 . 1 CC, establece que: «Procederá la aplicación análoga de las normas cuando éstas no contemplen un supuesto específico, pero regulen otro semejante entre los que se aprecie identidad de razón», por lo que debería ser de aplicación a los hijos mayores de edad (op. cit., pág. 577) y, CALvo ANTÓN, Manuela, establece que «el cuidado directo y la asistencia inmediata que desarrolla sobre los hijos el progenitor a cuyo cargo se ponen constituye una contribución en especie» («El nuevo artículo 93 del código civil y el sostenimiento de los hijos en la nulidad, separación o divorcio», La Ley: Revista jurídica española de doctrina, jurisprudencia y bibliografía, núm. 4, 1990, pág. 1123). 
puesto que el objeto de la pensión alimenticia es cubrir los gastos actuales del alimentista ${ }^{55}$.

VÁzQUEZ YruZUBIETA, acertadamente, dice que «será necesario hacer una distribución equitativa y no alícuota, no correspondiendo necesariamente a cada uno de los progenitores afrontar la mitad de los gastos» ${ }^{56}$, lo que se justifica en que la cantidad ha de ser "proporcionada» a los ingresos de ambos cónyuges ${ }^{57}$.

En síntesis, la colaboración de los litigantes para conocer sus verdaderos ingresos será necesaria para evitar situaciones que supongan un quebranto del criterio de proporcionalidad previsto por el artículo $146 \mathrm{CC}^{58}$.

En definitiva, la fijación de la cuantía de la prestación alimenticia a favor de los hijos mayores de edad estará en función de las necesidades del hijo y de la proporción en que han de contribuir los obligados a prestarla; la obligación alimenticia corresponderá prestarla a ambos progenitores, debido a que ambos presentan la misma proximidad de grado al descendiente [art. 144. 3 CC].

Sin embargo, conviene precisar que la exigencia prevista por el párrafo segundo del artículo 93 CC concretada en que el Juez fije los alimentos debidos a cargo de cada uno de los progenitores, con la única excepción de que uno de ellos quede excluido por carecer de recursos económicos -es decir, que la fijación de que los alimentos se realice a cargo de uno u otro de los progenitores, en función de la posibilidad o imposibilidad de poder prestarlos que presente cada uno de éstos-, comporta que si ambos cuentan con ingresos suficientes para poder afrontar dicha obligación, quedarán obligados y, por tanto, se deberá repartir entre éstos en cantidad proporcional a sus caudales respectivos.

\section{REQUISITOS PARA PODER RECLAMAR ALIMENTOS A FAVOR DE LOS HIJOS MAYORES DE EDAD EN EL PROCEDIMIENTO MATRIMONIAL}

Dice el párrafo segundo del artículo 93 CC: «Si convivieran en el domicilio familiar hijos mayores de edad o emancipados que care-

55 (AC: $1999 / 5921)$.

56 Op. cit., pág. 419.

57 Vid., la SAP de Ávila, de 14 de enero de 1998 (AC: 1998/226).

58 En este sentido, la STS, Sala de lo Civil, de 21 de diciembre de 1991, dispone que «a cada parte le corresponde la prueba de lo que conforme a la razón y la experiencia es más fácil de probar para ella que para la parte contraria» (RJ: 1991/9824). 
cieran de ingresos propios, el Juez, en la misma resolución, fijará los alimentos que sean debidos conforme a los artículos 142 y siguientes de este Código » ${ }^{59}$.

Del tenor literal del texto se deduce que para que el hijo mayor de edad o emancipado pueda reclamar alimentos de sus progenitores en los procedimientos matrimoniales, será necesaria la concurrencia de dos requisitos, siendo éstos, de una parte, que conviva en el domicilio familiar y, de otra, que carezca de ingresos propios -es decir, falta de independencia económica-.

En suma, para poder aplicar el mencionado párrafo será necesaria la existencia de un proceso sobre nulidad, separación o divorcio de los progenitores del hijo mayor de edad o emancipado y, la concurrencia de los requisitos específicos a que alude el precepto, debido a que la inexistencia de cualquiera de estos dos requisitos comportará que el hijo sólo pueda ejercitar su pretensión alimenticia acudiendo al juicio especial de alimentos provisionales o al juicio declarativo ordinario de alimentos definitivos que corresponda por cuantía ${ }^{60}$.

\section{Convivencia en el domicilio familiar y supuesto de traslado del hijo mayor de edad por razones de estudio}

Como se ha dicho, para que dentro del proceso matrimonial se pueda exigir la prestación de alimentos, el párrafo segundo del artículo 93 CC, exige el requisito específico de la convivencia en el domicilio familiar, con la finalidad de facilitar dicha prestación procesalmente, por tanto, para que sea factible, será necesario que el hijo mayor de edad o emancipado resida en el domicilio.

De modo que la permisibilidad del precepto radica en que la pretensión de alimentos del hijo dé origen a un proceso acumulativo al matrimonial para ser conocido y decidido junto a éste, debido a que la norma recoge aquellos supuestos en los que los hijos que alcanzan la mayoría de edad siguen viviendo en el domicilio familiar con dependencia económica de sus progenitores.

59 Este precepto es de aplicación a los hijos de parejas no casadas, como aclara STS, (Sala de lo Civil), de 30 de diciembre de 2000, todo ello, «en cumplimiento del artículo 39.2 (La Ley 2500/1978) CE en relación con el artículo 108 CC».

60 Vid., en este sentido, Belo GonzÁlez, Ramón: «Los alimentos de los hijos mayores de edad en el procedimiento matrimonial de sus progenitores», $A C$, 1-1991, pág. 29; Moreno Velasco, Víctor: «Los alimentos de los hijos mayores de edad en los procedimientos de separación, nulidad y divorcio», Diario La Ley, núm. 7433, 2010, pág. 2. 
En suma, mientras se mantenga dicha convivencia -es decir, que no se vea interrumpida por abandonar el hijo el domicilio familiar para hacer vida independiente-, se deberá facilitar procesalmente el reconocimiento del derecho de alimentos al hijo ${ }^{61}$.

MARÍn GARCía DE LEONARDO ${ }^{62}$ dispone que este requisito tiene como objeto establecer la justificación de la determinación de cómo se hacen efectivos los alimentos dentro de dicho proceso, así como que de la administración de éstos se encargue el progenitor con el que conviva el hijo. Esto se fundamenta en que los hijos deben contribuir equitativamente, según sus posibilidades, al levantamiento de las cargas de la familia mientras convivan en ella [art. 155. 2 CC].

$\mathrm{Al}$ respecto, PÉREz MARTín, señala que «resulta práctico al inicio de la ejecutoria, que comparezcan en autos los hijos mayores de edad manifestando que muestran su conformidad para que sea el progenitor con el que convive el encargado de administrar «su» pensión alimenticia o, bien designar la misma cuenta bancaria de este progenitor, para que se ingresen en ella «sus» pensiones» ${ }^{63}$.

Por otra parte, nuestros Tribunales de Justicia, partiendo de que ambos extremos -convivencia en el domicilio familiar y, carencia de ingresos propios- se encuentran vinculados entre sí, afirman que del hecho de la convivencia con uno de los progenitores se deduce una especie de presunción de falta de independencia económica que justifica la concesión de alimentos o su mantenimiento mientras no se destruya con la prueba en contrario.

En particular, la Sentencia de la Audiencia Provincial de Bilbao, de 19 de diciembre de 1991, establece que «el hecho de haber alcanzado la mayoría de edad no comporta el cese automático de la pensión fijada para los hijos debiendo acreditarse, para ello, que el hijo mayor de edad no depende de quien hasta el momento de cumplir los dieciocho años tenía su guardia y custodia ${ }^{64}$.

Por tanto, con la exigencia de este requisito, la no convivencia de los hijos mayores o emancipados en el domicilio familiar originará

61 Vid., Montero Aroca, Los alimentos a los hijos..., op. cit., pág. 240.

62 Régimen jurídico de alimentos..., op. cit., pág. 148.

63 La ejecución de las resoluciones..., op. cit., pág. 380.

64 En parecidos términos, la SAP de Pontevedra, de 27 de septiembre de 1991, señaló que «sería contrario a exigencias de equidad romper artificiosamente toda solución de continuidad de la situación familiar, por el solo dato de haber adquirido la mayoría de edad el hijo, sin que conste se haya alterado sustancialmente la razón de ser de la prestación asistencial, es decir, en tanto el hijo siga dependiendo económicamente de sus padres viviendo en el hogar familiar» (Puede verse el desarrollo de la Sentencia en RuIZ-Rico RuIz-Morón, op cit., págs. 1956-57). 
la no dependencia económica de éstos respecto de sus progenitores, originando la independencia económica de aquéllos y, en consecuencia, la tenencia de vida independiente, puesto que esta última, se deriva de la anterior.

En definitiva, la concurrencia de estos requisitos - es decir, vida independiente y separada de sus progenitores-comportan la imposibilidad de fijar alimentos por la vía del párrafo segundo del artículo 93 CC a los hijos mayores de edad o emancipados que no convivan en el domicilio familiar. Sin embargo, esto no significa que el hijo mayor de edad o emancipado no tenga derecho a una prestación de alimentos, sino que en caso de necesitarlo, deberá demandarlo a los progenitores por la vía de los artículos 1609 a 1616 LEC, es decir, que podrá ejercitar su pretensión alimenticia acudiendo al juicio especial de alimentos provisionales.

Por cuanto atañe a la facultad o no del hijo mayor de edad para solicitar la prestación alimenticia a sus padres. En particular, la Sentencia de la Audiencia Provincial de Barcelona, Sección 12. ', de 28 de febrero del 1996, denegó la solicitud de la prestación de alimentos reclamada por la madre en un proceso matrimonial, alegando que «la facultada para exigir a sus padres la satisfacción de sus necesidades alimenticias era la hija mayor de edad, ya que se trataba de un supuesto en el que la hija resultaba carente de ingresos propios y residía en el domicilio de unos tíos maternos desde hacía varios años, con el pleno consentimiento de sus padres. Por tanto, en este supuesto, la hija -en caso de necesidad- deberá demandar los alimentos a través del procedimiento de alimentos, debido a que no cabe solicitarlos en el proceso matrimonial, ya que reside en el domicilio de otros familiares ${ }^{65}$.

Otra cuestión directamente relacionada con la figura, y que ha sido objeto de controversias interpretativas doctrinales, se centra en la interpretación del requisito «convivencia en el domicilio familiar». Cuestión que ha sido salvada por el común de la doctrina ${ }^{66}$ al sostener que

65 (AC 1996/256) y, vid., las SSAAPP de Albacete, de 8 de mayo de 2006 y, de Asturias, de 14 de marzo de 2006.

66 Vid., Ruiz-Rico Ruiz-Morón, op. cit., pág. 1960; Martínez RodríGuez, Nieves: «Legitimación para reclamar alimentos a favor de los hijos mayores», $A C$, núm. 5, Sección Informe de Jurisprudencia, Quincena del 1 al 15 de marzo, 2008, p. 590, T. 1. La Ley (La Ley 943/2008), p. 3. En este sentido, Marín GARCÍA DE LEONARDO, opina que «no se interpreta en el sentido estricto del domicilio hasta que la situación de crisis haya tenido el matrimonio y los hijos, sino en el sentido más amplio de domicilio del progenitor con quien comparezca el hijo precisado de alimentos, coincida o no con aquél» (Régimen jurídico de alimentos..., op. cit., pág. 150). También, RuIz-Rico Ruiz-Morón, apoyándose en la SAP de Valencia, de 25 de noviembre de 1991, así lo preconiza al 
este término se debe interpretar en el sentido más amplio de domicilio del progenitor con quien finalmente permanezca el hijo precisado de alimentos y, no en el sentido estricto de domicilio que hasta la situación de crisis hayan tenido los progenitores y los hijos de éstos.

En suma, aunque para el reconocimiento del derecho de la pensión alimenticia a favor del hijo mayor de edad o emancipado, será necesario que éste resida en el domicilio conyugal o, en el de cualquiera de los dos progenitores con quien el hijo conviva al iniciarse el proceso matrimonial, lo cierto es que este presupuesto tendrá la consideración de concurrente en aquellos supuestos en los que el hijo por motivos de estudio se encuentre en otra localidad durante el curso lectivo al producirse el proceso en la crisis matrimonial -es decir, cuando su ausencia sea debida a causas justificadas o de carácter transitorio-.

En los casos del traslado del hijo mayor de edad por razones de estudio, doctrina ${ }^{67}$ y jurisprudencia menor ${ }^{68}$ coinciden en la inexis-

manifestar que «el hecho de que la hija en unión de la madre haya abandonado el domicilio familiar para ocupar en la actualidad una vivienda distinta, no hace escapar el supuesto de la incidencia beneficiosa del artículo 93.2 CC toda vez que la razón de su existencia radica en la presunción para el legislador de que la no convivencia de los hijos mayores o emancipados en el domicilio familiar es sinónima de su independencia económica, equiparando la autonomía de vida con la patrimonial. Por ello valdrá a los fines de su vigencia, tanto el domicilio conyugal propiamente dicho, como el de cualquiera de los progenitores con quien permanezca el hijo [...]» (op. cit., pág. 1957) y, GonZÁlez DEL Pozo, afirma que "por domicilio familiar debe entenderse tanto el domicilio conyugal, como el de cualquiera de los dos progenitores con quien el hijo conviva, debiendo estarse al momento o «lapso de tiempo» en que se suscita la crisis matrimonial a propósito de la cual se plantea el derecho de alimentos, para determinar si existe o no aquella convivencia» (op. cit., pág. 167). Por el contrario, BElo GonZÁlez, considera que los términos «domicilio y vivienda familiar» son idénticos y, por tanto, su conceptualización también debería serlo, poniendo de manifiesto, que «por vivienda y domicilio familiar se entiende aquélla en la que, inmediatamente antes de producirse el cese de la convivencia marital, residían ambos cónyuges en compañía en su caso, de sus hijos menores de edad, de forma permanente y estable» (op. cit., pág. 29). Y conforme a este autor, en los procedimientos en los que se dé la coyuntura de inexistencia de vivienda o domicilio familiar por cesar la convivencia marital (dejando tanto los cónyuges como los hijos de residir en dicho domicilio y pasando cada uno de los cónyuges a vivir en domicilios distintos y viviendo uno de ellos en compañía de su hijo), el hijo mayor de edad no podrá ejercitar su pretensión alimenticia, puesto que si se presenta la demanda de separación, divorcio o nulidad, y transcurrido el tiempo, el hijo vive con uno de los progenitores, pero no en el domicilio familiar, ya no concurre el requisito legalmente exigido.

67 Vid., Marín García de Leonardo, Régimen jurídico de alimentos..., op. cit., pág. 150; Montero Aroca, Los alimentos a los hijos..., op. cit., págs. 211 y ss.; GONZÁlez CARRASCO, op. cit., págs. 43 y ss.

68 La SAP de Cantabria, de 24 de septiembre de 1996, establece que «tal situación no implica necesariamente ruptura definitiva de la convivencia con la madre, que lógicamente se mantiene en periodos vacacionales» (La Ley: 10203/1996). En pare- 
tencia de abandono del domicilio familiar así como que tal supuesto no conlleva adquisición de independencia económica alguna, por lo que en ningún caso aparejará la extinción de la pensión alimenticia. En definitiva, el traslado no comporta necesariamente el incumplimiento del requisito de la convivencia.

Por tanto, no obsta a esa convivencia el hecho de que el hijo pase largas temporadas fuera de la vivienda familiar por razón justificada -por ejemplo, enfermedad, estudios-, si continúa teniendo en ella su domicilio y persiste su dependencia funcional y económica respecto del progenitor con quien convive ${ }^{69}$.

Con todo, para la jurisprudencial citada, lo determinante será si el hijo en los periodos vacacionales regresa al mismo o, por el contrario solo pasa cierto tiempo en éste de forma esporádica. En el primer caso se deberá entender que persiste la convivencia, mientras que en el segundo, se deduce que la continuidad ha dejado de existir ${ }^{70}$.

En definitiva, si el hijo mayor de edad se viera obligado a vivir, durante el curso lectivo en otro domicilio distinto del domicilio familiar -siempre que retorne al mismo en los periodos vacacionales-, no significará que haya abandonado el domicilio y obtenido independencia económica, debido a que estas ausencias se encuentran justificadas y, por tanto, no habrá lugar al cese de la obligación de la prestación alimenticia [art. $142^{71}$ CC].

cidos términos, en la SAP de Almería, Sección 2. ${ }^{\text {a }}$, de 14 de marzo de 2001, señala la fijación de la pensión alimenticia para las hijas de veintiuno y diecinueve años al decir que «si bien se encuentran por motivos de estudios en Almería, los fines de semana y vacaciones conviven con la madre, según propias alegaciones en confesión del padre, en el domicilio que fuera conyugal» (JUR: 2001/140451). También, la SAP de Granada, Sección $3 .{ }^{a}$, de 26 de octubre de 1998, establece que «la convivencia de la hija mayor del matrimonio con la actora no ha quedado desdicho por el hecho de que la misma se traslade por motivos de estudios a otra ciudad, habitando la vivienda de un familiar, ya que este domicilio tendrá la condición de eventual, en cuanto se limita a ciertos períodos de tiempo y sin una finalidad de estabilidad, lo que impide calificarlo como domicilio familiar, a que hace referencia el artículo 93.2 CC ya que éste no será otro que el que comparte con su familia, único domicilio propio de la referida hija» (AC: 1998/1892) y, la SAP de Girona, de 21 de marzo de 2006, reconoce que «es bastante común que los hijos, por razón de estudios, se trasladen a vivir a otra localidad, sin que por ello desaparezca el criterio de convivencia, Y, a sensu contrario, no se daría el presupuesto legal, si a pesar de vivir con un progenitor, el hijo mayor no depende él»

${ }^{69} \mathrm{Vid}$., Rivero HeRnÁNDEZ, op. cit., pág. 1072. En jurisprudencia, vid., la SAP de Álava, Sección 1. a , de 24 de mayo Rec. 115/2000.

70 Vid., Pérez Martín, La modificación y extinción..., op. cit., pág. 620; Moreno Velasco, op. cit., pág. 2.

71 «Los alimentos comprenden también la educación e instrucción del alimentista mientras sea menor de edad y aún después cuando no haya terminado su formación por causa que no le sea imputable». 


\section{Carencia de ingresos propios}

Por cuanto atañe al requisito de carencia de ingresos propios, conviene precisar que tanto la doctrina ${ }^{72}$ como la jurisprudencia menor reciente son coincidentes en que se debe interpretar como una falta de independencia económica -es decir, como una insuficiencia de ingresos- y, no en sentido literal -como absoluta necesidad de que el hijo carezca por completo de ingresos-.

Así, la doctrina ${ }^{73}$ mayoritaria sostiene que la falta o inexistencia de recursos ni debe ser imputable al hijo mayor de edad, ni interpretada de forma rigurosa, debido a que si éste tiene algún ingreso esporádico y exiguo no procederá la extinción, puesto que comportaría un perjuicio al progenitor con el que el hijo conviva, ya que tendría que sufragar la totalidad de sus necesidades.

En lo que a esta materia se refiere, la Sentencia de la Audiencia Provincial de Valencia, de 9 de abril de 1996, matizó que «una interpretación literal conduce a la conclusión de que no se deberá aplicar el párrafo segundo del artículo 93 y el hijo habrá de acudir al juicio de alimentos provisionales o al declarativo cuando disponga de ingresos propios, por exiguos que éstos sean, porque la previsión legal expresamente se refiere sólo a la "carencia» de ingresos y no a su «insuficiencia». Concepto éste que exige unos elementos de juicio acreditados y una actividad valorativa de su gravedad. Por el contrario, su interpretación racional, sistemática y teleológica nos lleva a entender que el hijo debe carecer de los ingresos propios «suficientes» para la satisfacción de las necesidades mencionadas en el artículo 142; pues, frente a la plena necesidad de recibir alimentos, en caso de que el hijo carezca por completo de tales ingresos, cabe hablar de la necesidad relativa en que se encuentra el hijo que, aun disponiendo de ellos, sean éstos insuficientes para cubrir sus necesidades ${ }^{74}$.

72 Vid., MARTÍNEZ RodRíguez, op. cit., p. 3.

73 Vid., Marín García de LeOnARdo, «La temporalidad de los alimentos..., op. cit., pág. 26; LáZaro PalaU, op. cit., pág. 32.

${ }_{74}$ (AC: 1996/800). En idéntico sentido, la SAP de Tarragona, de 6 de octubre de 1995, señaló que "procede ex artículo 93 CC la fijación de alimentos en favor de las hijas mayores de edad, siempre que carezcan de recursos propios y convivan en el domicilio familiar, debiendo interpretarse el citado requisito de falta de recursos propios del alimentista en el sentido de que no procederá la fijación de pensión cuando el hijo mayor de edad tenga ingresos suficientes para poder, por sí solo, hacer frente a sus necesidades, sin que sea dable enervar la obligación alimenticia del progenitor que no convive con sus descendientes por el hecho de que el hijo obtenga unos parvos e insuficientes ingresos» $\mathrm{y}$, añade la necesidad de interpretarlo conforme al artículo 3.1 CC., "de conformidad con la realidad social del tiempo en que han de ser aplicados, debiendo valorarse la gravísima crisis económica existente y el muy 
RuIz-Rico RuIz-Morón, afirma que esta sentencia sigue la línea marcada por otras en el sentido de que «la falta de ingresos propios, entendida como la falta de independencia económica es compatible con la realización de trabajos esporádicos o con la percepción de algún emolumento» ${ }^{75}$. Y, al respecto, MARÍN GARCía DE LEONARDO, añade que «de otra forma, bastaría que el hijo tuviera unos mínimos ingresos propios para eximir a sus progenitores de esta prestación alimenticia, que deberían pagar, en cambio, y en una idéntica situación de necesidad, tras otro pleito independiente y por mor de los

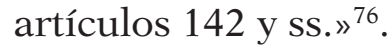

En virtud de lo anterior, está justificada la afirmación que sostiene que, no se trata tanto de falta absoluta de ingresos propios, como de que éstos sean claramente insuficientes para cubrir sus necesidades ${ }^{77}$.

En este punto, conviene precisar que el artículo 152. $3 \mathrm{CC}$, prevé como causa de extinción el hecho de que el alimentista pueda ejercer un oficio, profesión o industria y, salvo raras excepciones, la mera capacidad objetiva para el trabajo o el haber desempeñado con anterioridad algún trabajo parcial o en circunstancias precarias no impide la fijación de la pensión en el procedimiento matrimonial, debido a que de la Sentencia de la Audiencia Provincial de Las Palmas, de 15 de abril de 1994, se desprende que «en el momento actual de la situación laboral general, hablar de capacidad objetiva para el trabajo como causa extintiva de los alimentos suena a sarcasmo, ya que si el mercado laboral no facilita un puesto de trabajo la realidad es que el hijo mayor de edad no trabaja, por causa a él no imputable» ${ }^{78}$.

En definitiva, aún a pesar de la inexistencia de un criterio unánime por los Tribunales, lo cierto es que el derecho del hijo mayor de edad a percibir la pensión de alimentos no se extinguirá por el mero hecho de obtener algún ingreso por realizar trabajos de carácter parcial o por horas, debido a que no significa, con carácter general, capacidad para generar ingresos propios ${ }^{79}$, aunque sí se deberá tener en cuenta para determinar el importe de la pensión. Por tanto, para que proceda la extinción de la pensión, será necesaria la existencia de una posibilidad

elevado índice de desempleo juvenil de nuestra sociedad, a la hora de ponderar las exigencias de solidaridad familiar impuestas por las normas reguladoras de los alimentos paterno-filiales» (AC: 1995/1994).

75 Op. cit., pág. 1957.

76 Régimen jurídico de alimentos..., op. cit., pág. 142.

77 Vid., Montero Aroca, Los alimentos a los hijos..., op. cit., págs. 216; Martínez RodríGUEZ, op. cit., pág. 3.

78 (AC: 1994/745).

79 TSJC 12/2006, de 16 de marzo y, SAP de Barcelona, Sección 12. ${ }^{\text {a }}$, de 17 de julio de 2008. 
"real» $y$ "concreta» ${ }^{80}$ en relación con las circunstancias concurrentes y no una mera posibilidad en abstracto o hipótesis.

Sin embargo, aún a pesar de lo dicho, esto no significa que los alimentos del hijo mayor de edad solo queden extinguidos si el trabajo al que se accede es fijo y estable. En particular, la Sentencia de la Audiencia Provincial de Navarra, Sección 3. ${ }^{a}$, de 15 de mayo de 1996, estableció que «la precariedad de la situación laboral del hijo, ni el tipo de contratación son elementos extraños en el actual panorama sociolaboral [...] ${ }^{81} \mathrm{y}$, en consecuencia, esta precariedad, en la actualidad, pasa a formar parte característica del mercado laboral ${ }^{82}$.

Por el contrario, Belo GonzÁlez, señala que «si el hijo dispone de ingresos propios ya no concurre este requisito. Y ello aunque sus ingresos económicos ni siquiera le alcancen para cubrir sus alimentos [art. $142 \mathrm{CC}$ ] por lo que tendría derecho a ejercitar su pretensión alimenticia contra sus padres [art. 143.1. ${ }^{\circ} 2^{83} \mathrm{CC}$ ], pero no podrá hacerlo en el procedimiento matrimonial de éstos» ${ }^{84}$.

Frente a este argumento LÓPEZ-MUÑIZ GoÑ ${ }^{85}$, acertadamente dice que lo lógico es que el legislador hubiera hecho referencia a que el beneficio que se concedía fuera a aquellos hijos mayores de edad o emancipados que "carecieran de medios económicos para subsistir", con la finalidad de agrupar aquellos supuestos en los que el hijo dispusiera de algunos ingresos insuficientes para su mantenimiento.

En particular, la Sentencia de la Audiencia Provincial de Tarragona, de 7 de septiembre de 1995 (AC: 1995/1998), reconoció una pensión alimenticia a la hija mayor de edad pese a que ésta percibía una pensión por incapacidad laboral transitoria, consecuencia un accidente de tráfico, reconocimiento fundado en el estado de salud precario que sufre la alimentista y en el escaso montante de la pensión, por lo que ambos progenitores deberán contribuir a paliar las necesidades de toda índole de la hija. Por el contrario, la Sentencia de la Audiencia Provincial de Madrid, de 18 de septiembre de 1995 y,

$80 \quad$ SAP de Málaga, Sección 7. a , de 27 de febrero de 2006.

81 (AC: 1996/1578).

82 Vid., González Carrasco, op. cit., pág. 41. Desde el punto de vista jurisprudencial, la SAP de Barcelona, Sección 12. a, de 7 de julio de 1999 (AC: 1999/1201), en la cual el hijo mayor de edad obtiene algún ingreso trabajando tres horas por la tarde e incluso desarrollando alguna actividad con su padre, comportando ello no la extinción de la obligación, sino la reducción de la misma [...].

83 «1. Están obligados recíprocamente a darse alimentos en toda la extensión que señala el artículo precedente: 2 . Los ascendientes y descendientes».

84 Op. cit., pág. 30.

85 Op. cit., pág. 244. 
en aplicación del «criterio de subsistencia» no reconoció la pensión alimenticia al hijo mayor de edad, alegando que éste tenía un trabajo retribuido desde hacía varios años, concluyendo, a tal efecto, que éste le permitía subsistir con total independencia.

Aunque en ambos supuestos el montante obtenido -tanto de la pensión por incapacidad como del trabajo desempeñado- es escaso, su diferencia radica en que la resolución judicial del primer supuesto ha sostenido que el hecho de que el hijo mayor de edad reciba una ayuda económica por incapacidad no determina la extinción de la pensión alimenticia, debido a la posibilidad de que estos ingresos percibidos por la pensión de minusvalía no sean suficientes para atender sus necesidades -al ser superiores a las de cualquier otra persona-, considerándose ambas pensiones -es decir, la de incapacidad y la alimenticia- compatibles ${ }^{86}$. En el segundo caso, el hijo mayor de edad percibe una cantidad fija mensual durante varios años -no teniendo la calificación de trabajo esporádico, y pudiendo en consecuencia, hacer frente a sus necesidades por sí solo-, se ha incorporado al mercado laboral con un trabajo remunerado, por lo que no resultará aplicable lo dispuesto en el párrafo segundo del artículo $93 \mathrm{CC}$, al quebrantarse uno de los presupuestos necesarios -carencia de ingresos propios-.

Este nivel de subsistencia de los hijos es más acorde con el contenido del artículo 39. $3^{87} \mathrm{CE}$, que prevé un deber de asistencia de los padres, con la pretensión de que alcance al mantenimiento del hijo mientras no se pueda proveer por sí mismo a su adecuado sustento y, a los gastos de estudio o formación de cualquier tipo y, por tanto, esta obligación de los progenitores deberá persistir hasta el momento en que el hijo haya podido y debido conseguir una independencia económica ${ }^{88}$.

RuIZ-Rico RuIZ-MoróN ${ }^{89}$, acertadamente señala la inexigibilidad de estabilidad laboral para estimar concurrente la independencia económica, sino que más bien será decisivo que el empleo no sea esporádico, lo que se justifica en la argumentación esgrimida, entre

\footnotetext{
86 Vid., en la misma línea, las SSAAPP de Vizcaya, Sección 4. ${ }^{\text {a }}$, de 15 de enero de 2003 (AC: 2003/140) y de Orense, Sección 2. ${ }^{\text {a }}$, de 28 de mayo de 2002 (JUR: 2002/178934).

87 «3. Los padres deben prestar asistencia de todo orden a los hijos habidos dentro o fuera del matrimonio, durante su minoría de edad y en los demás casos en que legalmente proceda».

88 Vid., Roca I TRías, Encarna: «Comentario al artículo 93 del Código civil», en Comentario al Código civil, Ministerio de Justicia, T. I, Madrid, 1993, pág. 591.

89 Op. cit., págs. 1958.
} 
otras, por las Sentencias de la Audiencia Provincial de Toledo, Sección 1. ${ }^{a}$, de 15 de junio de 1992 (AC: 1992/946) y de 25 de marzo de 1998 (AC: 1998/607), al poner de manifiesto que los hijos mayores de edad, aunque convivan en el domicilio familiar, no cumplen el requisito para que se les reconozca el derecho a percibir la pensión de alimentos, ya que con independencia del carácter temporal o definitivo de su relación laboral, resulta acreditado en autos que vienen desempeñando un trabajo remunerado que les permite atender su propia subsistencia y las necesidades más elementales, lo que deja entrever su capacidad para procurarse un empleo, al margen de la mayor o menor estabilidad de su situación actual.

En suma, el párrafo segundo del artículo 92 CC, será de aplicación en los supuestos de insuficiencia o carencia total de ingresos por parte del hijo mayor de edad y, será necesario acudir al juicio de alimentos cuando el salario percibido por el hijo sea insuficiente para su manutención autónoma-siempre que siga conviviendo en el domicilio familiar-. Por tanto, el presupuesto de la carencia de ingresos propios deberá ser interpretado como insuficiencia, en el sentido indicado en las mencionadas sentencias.

\section{A) Supuesto de haber finalizado los estudios}

Esta cuestión es acreedora de opiniones jurisprudenciales contrapuestas. Así, un sector jurisprudencial, sostiene que el hecho de que el hijo mayor haya completado su formación no comporta causa de extinción de la pensión alimenticia, debido a que el hecho de haber finalizado los estudios, conforme a la realidad actual, no es garantía de una independencia económica.

De modo que esta se aboga por la subsistencia del deber de alimentos hasta que el hijo mayor de edad pueda hacer frente por sí mismo a sus necesidades -sin establecer a la ésta un límite temporal-. Posibilidad que debe ser entendida como «real» y «concreta» en relación con las circunstancias concurrentes y con ciertas posibilidades de permanencia y, no como una mera capacidad subjetiva de ejercer una profesión u oficio. Es decir, que los alimentos se mantengan mientras subsistan las circunstancias que sirvieron de base para su concesión y no se produzca uno de los casos previstos para su extinción [arts. 150 y $152 \mathrm{CC}$ ] sin que el transcurso del tiempo tenga por sí solo este efecto ${ }^{90}$.

90 Así, la SAP de Navarra, Sección 2. ${ }^{\text {a }}$, de 20 de diciembre de 1995, declaró respecto de un hijo mayor de edad que ha finalizado sus estudios universitarios, que «no resulta objetivamente exigible a dicho hijo, dada la realidad laboral 
En este sentido, Pérez MARTín, haciendo referencia a la Sentencia del Tribunal Supremo, Sala de lo Civil, de 5 de noviembre de 1984, señala que «no basta con tener un título que habilite para el ejercicio de una profesión, sino que será necesario contar con una oportunidad para el desempeño de ésta ${ }^{91}$. Y, añade que de ésta se desprende que "para que cese la obligación de prestación alimenticia, es preciso que el ejercicio de una profesión, oficio o industria sea una posibilidad concreta y eficaz según las circunstancias, no una mera capacidad subjetiva» ${ }^{92}$.

La adecuación a la realidad actual estará en función de que el hijo pueda haber accedido al mercado de trabajo -al depender ello de su voluntad-, sin perjuicio de que sea o no efectivo, debiendo tenerse en cuenta las dificultades que para el ejercicio de cualquier profesión $u$ oficio se presentan en la actualidad ${ }^{93}$.

Por el contrario, otro sector jurisprudencial, ha denegado la pensión alimenticia en función de la edad de los hijos y, de la finalización de unos estudios previos. Esta posición se justifica en que la pensión debe tener carácter temporal, no debiendo prestarse hasta que el hijo acredite un puesto de trabajo y, en consecuencia, si la necesidad del hijo proviene de la falta de interés en conseguir un medio de vida -por la comodidad que supone vivir a expensas de los padres-, la prestación se debe declarar extinguida.

En su virtud, que el hijo mayor de edad hubiera finalizado su formación académica deberá ser entendido como una mera capacidad subjetiva de ejercer una profesión u oficio y, no como una mera posibilidad «real» y «concreta», lo que se ha contrastado como Pérez MARTín manifiesta «con el elevado número de universitarios que a pesar de haber finalizado sus estudios se encuentran engrosando las listas del desempleo ${ }^{94}$. Y, por tanto, si los hijos no emplean la debi-

actual, que recién finalizada la carrera hubiera ya debido obtener un empleo y ser económicamente independiente, siendo obvias las dificultades al respecto» (AC: 1995/2454). También, la SAP de Ciudad Real, Sección 1. a , de 9 de mayo de 2002 (JUR: 2002/177890), pone de manifiesto que, en la actualidad, lo normal es que tras terminar los estudios, pase un periodo de tiempo hasta que se accede al mercado de trabajo, por lo que aún cuando los hijos hayan finalizado su carrera universitaria, no habiendo logrado todavía un puesto de trabajo que les permita independizarse, procede mantener la pensión alimenticia, puesto que no existe ninguna razón para que se suprima la misma, salvo que se acredite alguna de las causas que con relación a este tipo de pensiones se establecen en el CC para denegarla o hacerla cesar [art. $152 \mathrm{CC}]$.

91 (RJ: 1984/5367).

92 El procedimiento contencioso..., op. cit., pág. 468.

93 Vid., Montero Aroca, Los alimentos a los hijos..., op. cit., págs. 220 y ss.

94 La modificación y extinción..., op. cit., pág. 616. 
da diligencia en la búsqueda de un puesto de trabajo o, si a pesar de tener la posibilidad de desempeñar un puesto de trabajo no lo hacen, deberá cesar la prestación alimenticia.

En este sentido, la Sentencia del Tribunal Supremo, Sala de lo Civil, de 1 de marzo de 2001, denegó una pensión alimenticia a dos hijas mayores de edad, licenciadas en Derecho y Económicas. Señalando que «teniendo además en cuenta, que a tenor de lo dispuesto en el artículo 3.1 CC que determina que las normas se interpretarán atendiendo a la realidad social del tiempo en que han de ser aplicadas, no cabe la menor duda que no hay base suficiente para que siga vigente tal obligación alimenticia. Se dice lo anterior porque dos personas graduadas universitariamente, con plena capacidad física y mental y que superan los treinta años de edad, no se encuentran hoy por hoy en una situación que se pueda definir de necesidad, que les pueda hacer acreedoras a una pensión de alimentos, lo contrario sería favorecer una situación pasiva de lucha por la vida, que podría llegar a suponer un parasitismo social $»^{95}$.

\section{B) Supuesto de continuación de los estudios}

En este punto encontramos dos corrientes doctrinales ${ }^{96}$ claramente diferenciadas. De una parte, la quienes sostienen que el hijo mayor de edad, poseyendo la edad adecuada, continúa sus estudios con aprovechamiento, con la finalidad de ampliar su formación y, de otra, la de quienes estiman que el hijo mayor de edad, también con la edad adecuada continúa sus estudios, pero con un rendimiento bajo o sin el aprovechamiento debido.

Por cuanto al primer supuesto se refiere, la jurisprudencia menor ${ }^{97}$ es partidaria del mantenimiento de los alimentos. Sin embargo, aunque del CC se desprende que para la supresión de la pensión a favor de un hijo mayor de edad hace falta que éste tenga ingresos propios de carácter fijo o, una formación ya terminada que le per-

95 (RJ: 2001/2562) y, en la misma línea, la SAP de Valencia, Sección 10. a, de 10 de marzo de 2003 (JUR: 2003/141959), procedió a la extinción de la pensión alimenticia de la hija de veintinueve años de edad, sin trabajo, pero con estudios universitarios terminados, argumentando que a la vista de los hechos, ésta cuenta con una madurez y una preparación que le permite valerse por sí misma e impide considerarla dependiente de la ayuda de sus padres, por lo que no procede la fijación de alimentos.

96 Vid., Montero Aroca, Los alimentos a los hijos..., op. cit., págs. 222 y ss.; Marín García de LeOnARdo, Régimen jurídico de alimentos..., op. cit., págs. 147 y ss.

97 Vid., la SAP de Tarragona, de 31 de marzo de 1995 (AC: 1995/761). 
mita obtener un puesto de trabajo como posibilidad real y cierta, lo cierto es que dicho pronunciamiento -de carácter general- puede ser inaplicable en aquellos supuestos de carácter excepcional en los que debido a la avanzada edad del hijo y por su negligente conducta, la falta de puesto de trabajo o de terminación en sus estudios, provoque una carga gravosa para el progenitor. Por ejemplo, el hijo mayor de edad que realiza «actividades» o «cursos» innecesarios para su formación, con la finalidad de alegar su derecho a percibir alimentos de su progenitor.

En este punto, MaRín GARCía DE LEONARDO ${ }^{98}$ se plantea -caso de que sean los progenitores quienes costeen los estudios de los hijos mayores de edad- hasta qué punto pueden los hijos imponer su interés de seguir matriculándose en diferentes actividades complementarias a los estudios realizados, cuando ya están en condiciones de obtener o ayudar a su propia autonomía económica.

En estas situaciones sería conveniente establecer una pensión de alimentos temporal, cuando se hayan terminado los estudios y, los que resulten complementarios sean compatibles con alguna actividad laboral remunerada, con la finalidad de evitar prolongaciones voluntarias e innecesarias de la situación de dependencia económica de los hijos respecto de los progenitores ${ }^{99}$.

Supuestos asimilables a aquellos otros en los que el hijo se encuentra preparando oposiciones ${ }^{100}$-carente de ingresos propios-, con la pretensión de obtener un empleo público en propiedad y que, como norma general, requieren de un periodo amplio de preparación.

En suma, aunque esta postura jurisprudencial aboga por el mantenimiento del derecho, lo cierto es que la obligación alimenticia de los hijos mayores no puede tener un carácter incondicional e ilimitado en el tiempo, por lo que resulta necesario tener en cuenta tanto la capacidad económica del progenitor, como la edad del hijo, debiendo establecerse un límite temporal a ésta, debido a que la continuidad de la etapa

98 «La temporalidad de los alimentos..., op. cit., pág. 21.

99 En este sentido, la SAP de Álava, de 28 de febrero de 1996, consideró que la preparación del Doctorado (por el hijo mayor de edad, el cual ya había finalizado unos estudios universitarios previos), era compatible con la realización de una actividad laboral remunerada.

100 La SAP de Baleares, Sección 5. ${ }^{\text {a de }} 28$ de febrero de 2005 (JUR: 2005/90808), mantiene la pensión alimenticia a favor del hijo mayor de edad que ha concluido sus estudios, pero depende económicamente del progenitor con el que convive, al estar preparando oposiciones, hasta un periodo máximo de un año. Con independencia de que concluido el mismo, el hijo haya aprobado o no las mismas y éstas se hubieren o no convocado, deberá procederse a la extinción de la misma. 
formativa no sólo depende de la decisión del hijo, sino también de las posibilidades con que cuente el progenitor para sufragarlas.

Por lo que al segundo caso atañe, pese al nulo o escaso rendimiento académico, buena parte de la doctrina y jurisprudencia ${ }^{101}$ ha sido unánimes en el mantenimiento del derecho, debido a que esta causa por sí sola no comporta la extinción del derecho de alimentos concedidos por la vía del párrafo segundo del artículo $93 \mathrm{CC}$; pero ésta unida a la edad con que cuenten los alimentistas, podría aconsejar someter dicho derecho a la fijación de un límite temporal, a partir del cual se presumirá imputable al alimentista la no terminación de su periodo de formación, salvo que realice estudios universitarios de mayor duración, mientras éstos no concluyan y, siempre que exista un adecuado aprovechamiento.

Otro sector doctrinal, entiende -con acierto que no es correcta la fijación de los alimentos en el procedimiento matrimonial en el que no concurren los requisitos del párrafo segundo del artículo 93 CC, condicionando su ejecución a que se den en su día, debido a que se trata de una medida de carácter excepcional y, por tanto, no se puede adoptar de forma condicionada al hecho de que sus presupuestos se cumplan en el futuro, ya que esto es lo que se realmente se deberá analizar en su petición.

Así, González CARRAsco ${ }^{102}$-con acierto- entiende que, la Sentencia de la Audiencia Provincial de Navarra, Sección 3. ${ }^{a}$, de 20 de febrero de 1997 (AC: 1997/390), ha realizado una interpretación errónea, debido a que no se debe confundir esta causa de extinción de la obligación de los alimentos con la partida alimenticia que corresponde a los hijos mayores de edad en concepto de educación «siempre que no hayan terminado su formación por causa que no les sea imputable». Si bien, la no realización por parte del hijo beneficiario de la pensión de una actividad de formación estudiantil o profesional no debe determinar la supresión de los alimentos fijados en el procedimiento matrimonial si sigue conviviendo en el domicilio familiar y carece de ingresos propios, a no ser que esta inactividad académica se pueda considerar falta de aplicación al trabajo. Supuesto en el que se deberá proceder a reducir la pensión de alimentos por reducción de los gastos alimenticios, pero no a la extinción de la obligación.

En cuanto al mantenimiento del derecho, la ausencia de unanimidad jurisprudencial, ha dado origen a opiniones controvertidas y,

101 Vid., las SSAAPP de Valencia, Sección 7. ${ }^{\text {a }}$, de 26 de septiembre de 1995 (AC: 1995/1560); de Guadalajara, de 12 febrero de 1996 (AC: 1996/361).

102 Op. cit., pág. 41. 
en consecuencia, a la inexistencia de un único criterio de aplicación sobre la materia.

De una parte, aquellas partidarias en limitar temporalmente la duración de la pensión alimenticia -como sería el caso de la limitación a cinco años desde la presentación de la demanda esgrimiendo como justificación «el que se limité la prestación de alimentos a un tiempo prudencial al término del cual los hijos habrán finalizado ya los estudios, y estarán en disposición de desempeñar algún trabajo, es más que razonable para que los hijos terminen los estudios que tienen proyectado cursar» ${ }^{103}$; De otra, aquellas que sostienen que la posibilidad de modificar la medida no permite establecer una limitación temporal previa ${ }^{104}$.

En síntesis, de los pronunciamientos jurisprudenciales se evidencia la propensión por el juez de adoptar el mantenimiento del derecho, pero limitando éste a un tiempo prudencial e, incluso se valora esta circunstancia en casos extremos -siempre que el hecho sea probado- como una causa de extinción del derecho, debido a que la pensión alimenticia de los hijos mayores de edad no tiene carácter indefinido ni es vitalicia, pudiendo cesar por una actitud negligente del hijo.

Por ejemplo, en el supuesto de que el progenitor obligado alegue como causa de extinción o reducción de la pensión alimenticia -alegato que deberá quedar probado en autos- que el hijo mayor de edad no asume sus obligaciones y, que por el bajo rendimiento en sus estudios suspende de forma reiterada en los cursos académicos en los que se matricula, será necesario realizar una valoración de la conducta del hijo y, analizar las causas por las que no ha finalizado los estudios. Circunstancia que se deberá tener en cuenta para fijar una limitación temporal de la prestación de alimentos, calculando el tiempo en el que prudencialmente debe finalizar sus estudios y estar en disposición de desempeñar un trabajo ${ }^{105}$.

En suma, el bajo o nulo rendimiento de los estudios no tendrá - cuando la causa no sea imputable al hijo- la consideración de causa de extinción de la prestación alimenticia a favor de éste, pero sí será

103 Vid., SAP de Barcelona, Sección 12. ${ }^{\text {, }}$, de 17 de mayo de 1996 (AC: 1996/1893).

104 Vid., las SSAAPP de Barcelona, Sección 12. ${ }^{a}$, de 25 de mayo de 1998 (AC: 1998/5430) y, de Madrid, de 20 de junio de 1995 (AC: 1995/1267).

105 Vid., Marín García De LeONARdo, Régimen jurídico de alimentos..., op . cit., págs. 147-148. Desde el punto de vista jurisprudencial, la SAP de Barcelona, Sección 12. a , de 17 de mayo de 1996, señaló que «no es admisible que la obligación de alimentos quede sin efecto por el hecho de que los hijos no rindan en los estudios lo que es de desear, sí lo es que se limité la prestación de alimentos a un tiempo prudencial» (AC: 1996/893). 
tenido en cuenta para establecer un limite temporal, con la finalidad de evitar una prolongación de la prestación con carácter perpetuo, debido a que la pensión alimenticia de los hijos mayores de edad ni tiene carácter indefinido, ni es vitalicia, pudiendo ésta cesar frente a una conducta negligente del hijo.

Respecto a la temporalidad fijada como una consecuencia del bajo o escaso rendimiento académico, conviene precisar que el establecimiento de las pensiones alimenticias con carácter temporal dentro de las medidas adoptadas en sentencia de separación, nulidad o divorcio, se fundamenta en la edad del hijo unida al bajo rendimiento académico obtenido por éste. De ahí que, en la actualidad, sea frecuente encontrarnos con señalamientos de pensiones de esta índole, dada la situación concreta de los hijos mayores de edad, debiendo tenerse presente que siempre les cabe la posibilidad de que, llegado al límite impuesto, acrediten la persistencia de la necesidad de seguir percibiendo alimentos, por medio de la vía procesal autónoma pertinente -en defensa de sus derechos alimentarios-, para que se le pueda aplicar la referencia del artículo $142 \mathrm{CC}$ al no haber terminado su formación por causas que no les son imputables.

No obstante, se observa la existencia de pronunciamientos judiciales en los que la limitación temporal se ha realizado sin hacer referencia al escaso o nulo aprovechamiento de los estudios, estableciéndose limitaciones temporales en función únicamente de la edad del hijo. En particular, la Sentencia de la Audiencia Provincial de la Rioja, Sección Única, de 1 de abril de 1998, estableció que «si bien es cierto que la obligación de alimentos a favor de los hijos mayores de edad subsiste mientras subsisten las necesidades del hijo beneficiado, tal obligación no puede establecerse a perpetuidad»106.

Por tanto, aunque se dice que la obligación alimenticia es indeterminada en el tiempo -ya para evitar posibles prolongaciones voluntarias en el tiempo por parte del hijo ya por razones de apatía en detrimento del padre obligado-, lo cierto es que gran parte de la doctrina se inclina por la posibilidad de que la obligación alimenticia se acote en el tiempo.

Tanto doctrina como jurisprudencia menor son coincidentes en la conveniencia de una limitación temporal, concretando que los alimentos se hagan efectivos hasta la edad determinada por el Juez -cifrada ésta como norma general en los veintiséis o veintisiete ${ }^{107}$

106 (AC: $1998 / 4585)$.

107 Así se desprende de la STS, Sala de lo Civil, de 30 de diciembre de 2000 (RJ: 2000/10385). 
años-. Esta edad que puede en ocasiones ser inferior ${ }^{108}$ sin necesidad de acreditar una causa que justifique la limitación, tiene como finalidad que «con la limitación de la pensión el beneficiario sabe que a partir de un concreto momento deberá valerse por sí mismo» ${ }^{109}$. Sin embargo, últimamente, esta limitación temporal no cuenta con un criterio único para su fijación, cuando lógico sería que éste estuviera establecido.

\section{C) Capacidad económica de los progenitores}

En este sentido, tanto la doctrina ${ }^{110}$ como la jurisprudencia son unánimes al establecer que no cabe duda que no se puede cargar la decisión de los hijos mayores de edad de realizar estudios y no acceder a un trabajo remunerado sobre la escasa capacidad económica de los progenitores. De modo que será necesario tener en cuenta la capacidad económica de éstos, no debiéndose en el supuesto de que sea escasa cargar sobre ellos la decisión de continuar unos estudios si el hijo mayor de edad o emancipado ha podido optar -por sus condiciones-, entre incorporarse a la vida laboral o continuar estudiando, e incluso realizar de forma conjunta ambas cosas.

En particular, la Sentencia de la Audiencia Provincial de Las Palmas de Gran Canarias, Sección 3. ${ }^{a}$, de 13 de junio de 1996, destaca que la opción de los hijos mayores de edad entre una continuación de los estudios o su orientación a la vida profesional o laboral es libérrima, debido a que los padres a partir de la extinción de la patria paterno-filial, carecen de facultades legales para orientar la vida laboral o profesional de sus hijos, subsistiendo el derecho a

108 En las SSAAPP de Pontevedra, Sección 1. ${ }^{\text {, }}$, de 15 de enero de 1998 (AC: 1998/53); de Guipúzcoa, Sección 3. a , de 15 de diciembre de 1998 (AC: 1998/2460) y, de Guipúzcoa, de 12 de marzo de 1999 (AC: 1999/548), se estimó que la fijación de un límite de edad a la obligación de alimentos antes configurada es conforme al Derecho ya que «la prolongación de la pensión de alimentos hasta la independencia económica o los veintitrés años, es una medida razonable y acorde, vía analogía, con el artículo 93.2 CC y el artículo 152.5 CC al contrario, mantener, indefinidamente una medida propia de la patria potestad es contrario a la finalidad de la norma y al equilibrio de los intereses a juego, pues supone mantener al mayor de edad en una especie de capitidisminución y alterar la posición de los dos obligados al pago de alimentos, cuando proceda tal obligación conforme a Derecho». Mientras que otras, como sería la SAP de Barcelona, Sección 12. ${ }^{\text {a }}$, de 25 de mayo de 1998 (AC: 1998/5430), señala como límite los veinticinco años.

109 Vid., SSAAPP de Guipúzcoa, Sección 2. ${ }^{a}$, de 11 de mayo de 1998 (AC: 1998/967) y, de Palencia, de 24 de marzo de 1998 (AC: 1008/546).

110 Vid., Marín García de LeOnardo, Régimen jurídico de alimentos..., op . cit., págs. 148 y ss.; AguILAR RuIZ, op. cit., págs. 333 y ss. 
los alimentos cuando esté saneada la capacidad económica de sus progenitores, siempre que la opción suponga la continuación de los estudios después de los dieciocho años, «pero cuando la capacidad paterna es escasa, y el hijo ha podido optar, por sus condiciones laborales entre incorporarse a la vida laboral o continuar estudios, o bien incluso fórmulas mixtas comunes en otros países de nuestro entorno cultural, no puede pretenderse cargar la decisión a favor de realizar estudios y no acceder a trabajo remunerado sobre la escasa capacidad económica del padre» ${ }^{111}$.

Sin embargo, en los supuestos en los que el hijo tras la finalización de una formación previa, se encuentra preparando oposiciones que requieren de un periodo amplio de preparación, será de aplicación el análisis casuístico, puesto que la prórroga de la etapa formativa depende, tanto de la decisión del hijo como de las posibilidades económicas que tengan los progenitores. Por tanto, si éstas son escasas, no se deberá cargar sobre ellos la decisión de la continuación de los estudios, máxime cuando el hijo se encuentra en condiciones de poder obtener su propia autonomía personal.

\section{La carga de la prueba}

La inexistencia de aclaración de forma expresa por el párrafo segundo del artículo $93 \mathrm{CC}$ sobre la parte que ha de soportar el onus probandi, y dada la ambigüedad que de forma implícita comportan los requisitos de la "convivencia en el domicilio familiar» $\mathrm{y}$, "carencia de ingresos propios» por el hijo mayor de edad, ha provocado la concurrencia de opiniones contrapuestas y corrientes doctrinales no coincidentes.

Por cuanto atañe al primer presupuesto, acertadamente MONTERo AROCA aprecia que «el requisito deberá ser alegado y probado por el progenitor que pide los alimentos para los hijos mayores de edad. Ello se fundamenta en el artículo 1214 CC, al establecer que «incumbe la prueba de las obligaciones al que reclama su cumplimiento [...]». Y, añade que «no se debería tratar de presumir nada, sino de estar a la realidad y a la condición de la familia, debiendo aplicarse para ello la "teoría de la facilidad probatoria" »112.

En idéntico sentido, la Sentencia de la Audiencia Provincial de Madrid, Sección 22. ', de 1 de febrero de 2000, establece que «la experien-

\footnotetext{
111 (AC: 1996/1151).

112 Los alimentos a los hijos..., op. cit., pág. 204.
} 
cia demuestra que, en frecuentes ocasiones, la disgregación familiar derivada de la separación, divorcio o nulidad conlleva el que el progenitor obligado al pago acabe por desconocer la situación convivencial, formativa y laboral del beneficiario del derecho, lo que a veces viene provocado por la ocultación de tales circunstancias por parte de éste, o el progenitor con el que convive, al referido alimentante. Arrojar por entero, bajo tales hipótesis, sobre el obligado al pago la carga de acreditar la posible concurrencia de circunstancias o causas extintivas del derecho de alimentos podría implicar una auténtica indefensión, por la dificultad que ello puede conllevar [...]» ${ }^{113}$.

Por el contrario, Belo González, establece que «la carga de la prueba debería incumbir al hijo mayor de edad». Y, añade que «atendiendo a las circunstancias propias de nuestra sociedad actual, hasta una determinada edad del hijo, debería establecerse una inversión en la carga de la prueba, de forma que incumbiera la carga de la prueba de que el hijo ya no reside en el domicilio familiar a cualquiera de los progenitores» ${ }^{114}$.

Por lo que al segundo requisito se refiere, Montero Aroca ${ }^{115}$, declara que, en principio, todo apunta a que deberá probar la carencia de recursos quien pida los alimentos para el hijo mayor de edad, debido a que del artículo 1214 CC se desprende que «incumbe la prueba de las obligaciones al que reclama su cumplimiento [... ${ }_{»^{116}}$.

Por el contrario, Belo GonzÁlez, afirma que la carga de la prueba «incumbe a aquél de los cónyuges que afirme que el hijo obtiene ingresos económicos propios» $\mathrm{y}$, añade que «en el supuesto de que el hijo haya adquirido la mayoría de edad durante la tramitación del procedimiento ha de presumirse la necesidad de que es acreedor de tal pensión alimenticia, ya que se encuentra cursando estudios y no se le conocen medios propios de subsistencia» ${ }^{117}$. De modo que quien afirme lo contrario deberá probarlo.

\footnotetext{
113 (AC: $2000 / 110)$.

114 Op. cit., págs. 30 y ss.

115 Los alimentos a los hijos..., op. cit., págs. 224 y ss.

116 En la idéntica línea, la SAP de Barcelona, Sección 12. a de 17 de enero de 1996 (AC: 1996/56) -en el caso de una solicitud de alimentos para un hijo mayor de edad-, argumentó que la esposa apelante, a tenor de lo previsto en el artículo 1214 CC debía haber acreditado los dos presupuestos previstos por el párrafo segundo del artículo 93 CC -convivencia a costa de uno de los progenitores y dependencia económica de éstos-, para el mantenimiento de la obligación alimenticia y en ausencia de apoyo probatorio, conviene en el desistimiento del recurso.

117 Op. cit., pág. 30 y ss., vid., la SAP de Badajoz, Sección 2. ${ }^{a}$, de 1 de septiembre de 1999, (AC: 1999/6120).
} 
De modo que no se debería tratar de presumir nada, sino de estar a la realidad y a la condición de la familia aplicando para ello la «teoría de la facilidad probatoria», debido a que en los supuestos de separación, divorcio o nulidad, el progenitor no conviviente con el hijo mayor de edad, como norma general, desconoce su situación laboral o de estudios, debido a diversas circunstancias. Por tanto, lógico sería que recayera la carga de la prueba sobre el progenitor que reclama su cumplimiento, es decir, sobre el progenitor conviviente con el hijo mayor de edad ${ }^{118}$, debido a que la prueba de los datos estará más al alcance del progenitor conviviente que del no conviviente.

En definitiva, la carga de la prueba deberá recaer sobre el progenitor que solicita los alimentos para los hijos mayores de edad -es decir, el progenitor conviviente-, debido a que la acreditación de la prueba de la existencia o no de dicha convivencia estará más al alcance de éste-de acuerdo con la «teoría de la facilidad probatoria»-que del progenitor no conviviente. Progenitor último que, como norma general, en los supuestos de separación, divorcio o nulidad, desconoce la situación del hijo - al no tener ningún tipo de contacto con el mismo, bien por residir en distinta ciudad o, por omisión de información por parte del hijo o del progenitor conviviente con éste- $y$, por tanto, este desconocimiento le comporta una mayor dificultad probatoria sobre la no convivencia del hijo en el domicilio del otro progenitor.

\section{EXTINCIÓN DE LA OBLIGACIÓN ALIMENTICIA A FAVOR DE LOS HIJOS MAYORES DE EDAD: SUPUESTOS}

Por cuanto atañe a la extinción de la obligación alimenticia, la circunstancia de que el hijo haya alcanzado la mayoría de edad no es suficiente para suprimir la pensión de alimentos. De modo que doctrina $^{119}$ y jurisprudencia menor coinciden al establecer que «la mayoría de edad no comporta de modo automático la extinción de la pensión alimenticia, pues la propia realidad social [art. 3.1 CC] demuestra que los hijos, aún adquirida la mayoría de edad, y extinguida la patria potestad, continúan bajo la dependencia económica de sus padres, habida cuenta de la especial dificultad que supone hoy en día acceder al mercado de trabajo con objeto de obtener unos ingresos que le permitan realizar una vida independiente de sus progenitores» ${ }^{120}$.

118 Vid., Montero Aroca, Los alimentos a los hijos..., op. cit., pág. 215; también vid., la SAP de Madrid, Sección 22. ${ }^{\text {, }}$, de 1 de febrero de 2000 (AC: 2000/110).

119 Vid., Pérez Martín, La modificación y extinción..., op. cit., pág. 607.

120 La SAP de Cáceres, Sección 2. a, de 11 de junio de 1999 (AC: 1999/5681). 
En particular, la Sentencia de la Audiencia Provincial de Ávila, Sección 1. ${ }^{a}$, de 8 de enero de 2004, precisa que «que es necesario distinguir entre la mayoría de edad civil y la independencia económica, con lo que, esta circunstancia ha llevado a la Jurisprudencia a expresar que la mayoría de edad no es un dato suficiente para suprimir la ayuda, pues en atención al contenido del artículo 93.2 CC, los alimentos de los hijos mayores se fundamentan, no en el indudable derecho de esos hijos a exigirlos de sus padres, sino en la situación de convivencia en que se hallan respecto a uno de los progenitores, convivencia que no puede entenderse como el simple hecho de morar en la misma vivienda, sino que se trata de una convivencia familiar en el más estricto sentido del término con lo que la misma comporta entre las personas que la integran» ${ }^{121}$.

En suma, la pensión alimenticia de los hijos -establecida conforme al párrafo segundo del artículo 93 CC- no se extinguirá por alcanzar la mayoría de edad, debido a que ésta se mantendrá mientras éstos sigan conviviendo con uno de los progenitores, no conforme a la patria potestad prevista en el artículo 154, sino a la «obligación alimenticia entre parientes» [arts. 142 y ss., CC], siempre que no concurra alguna de las causas de extinción del deber de alimentos [arts. 150 y 152 CC] sin perjuicio, en los supuestos de cese de la pensión, de que acreditada de nuevo la necesidad en un momento posterior por el hijo mayor de edad, pueda éste reclamar nuevamente los alimentos a sus progenitores, pero indudablemente fuera del procedimiento matrimonial.

\section{Extinción de la pensión en el supuesto de que el hijo no conviva con el progenitor}

Como ya se ha anunciado, el establecimiento de los alimentos a los hijos mayores de edad dentro del procedimiento matrimonial atiende a los criterios previstos en el párrafo segundo del artículo 93 CC -convivencia en el domicilio familiar y falta de recursos económicos propios-, lo que se constituye como una excepción al régimen general de «alimentos entre parientes», debido a que su fijación se encuentra condicionada a un requisito -convivencia con uno de los progenitores- que no se encuentra incluido en los artículos 142 y ss.

Frente a la cuestión de si será o no causa de extinción de la pensión alimenticia a favor de los hijos mayores de edad, el cese de la convivencia en el domicilio familiar. La doctrina mayoritaria la ha

121 (JUR: 2004/79506). Y, vid., la STS, de 24 de abril de 2000 y, la SAP de Ávila, de 6 de septiembre de 1996. 
resuelto positivamente, debido a que si la pensión de alimentos fue concedida en atención a la existencia de dicho requisito y, con posterioridad, el hijo ha dejado de convivir en el domicilio, se origina un cambio de las circunstancias que concurrieron en aquel momento. Por tanto, lógico es que se proceda a la extinción de la pensión, lo que se justifica en que el párrafo segundo del artículo $93 \mathrm{CC}$, únicamente permite que se fije la pensión a los hijos que conviven en el domicilio familiar.

Así, Pérez Martín, estima que «si en el momento de la separación o divorcio existían hijos que no convivían en el mismo, la sentencia matrimonial nunca podría fijar una pensión alimenticia para éstos, por lo que si éstos tenían derecho a alimentos deberían reclamarlos a través del correspondiente procedimiento de alimentos entre parientes ${ }^{122}$.

Por su parte, la jurisprudencia menor, establece que el cese de la convivencia del hijo mayor de edad en el domicilio se equipará a la situación de los hijos que no convivían en el domicilio en el momento de la separación o divorcio, procediéndose por tanto, en ambos casos, a la extinción de la pensión de alimentos dentro del proceso matrimonial ${ }^{123}$.

Otra cuestión de interés, reside en determinar el momento del abandono efectivo por el hijo del domicilio o de la convivencia con el progenitor en los supuestos de traslado del hijo mayor de edad por razones de estudio. Cuestión salvada por la doctrina ${ }^{124}$ y jurisprudencia $^{125}$ al prever que la consideración de continuidad de la convivencia

122 La modificación y extinción..., op. cit., pág. 620.

123 La SAP de Madrid, Sección 24. ${ }^{a}$, de 27 de junio de 2002 (JUR:2002/226677), procedió a la extinción de la pensión alimenticia de la hija mayor de edad al haber dejado de convivir con la madre en el domicilio familiar, puesto que no tiene ya razón de ser el mantenimiento de una pensión de alimentos a favor de la misma, al faltar el presupuesto previo para el mantenimiento de la pensión (convivencia en el domicilio), cuando de hecho no convive con la madre, produciéndose así con la independencia de la hija una sustancial modificación de las circunstancias. En los mismos términos, la SAP de Vizcaya, Sección 4. ${ }^{\text {, }}$ de 5 de julio de 2004 (JUR: 2004/306121), suprimió de la pensión alimenticia a favor de la hija, dado que no residía en el domicilio familiar, situación de hecho que impide que entre dentro del ámbito del artículo 93.2 CC, al exigir la convivencia del hijo mayor de edad en el domicilio familiar para señalar pensión a cargo del otro progenitor, sin perjuicio en ambos casos de que en el supuesto que el hijo necesite alimentos los reclame por la vía ordinaria.

124 Vid., Pérez Martín, La modificación y extinción..., op. cit., pág. 620; Moreno Velasco, op. cit., pág. 2.

125 Vid., en este sentido, entre otras, las SSAAPP de Cantabria, de 24 de septiembre de 1996 (La Ley: 10203/1996); de Almería, Sección 2. a , de 14 de marzo de 2001, (JUR: 2001/140451); de Granada, Sección 3. a , de 26 de octubre de 1998, (AC: 1998/1892) y, de Girona, de 21 de marzo de 2006. 
en el domicilio familiar radicará en si el hijo regresa al domicilio en los periodos vacacionales o fines de semana -en este caso- se entiende la persistencia de la convivencia, mientras que por el contrario, si únicamente pasa cierto tiempo en el mismo de forma esporádica, la convivencia ha dejado de existir [Párrafo segundo del art. $93 \mathrm{CC}$ ].

\section{Extinción de la pensión en el supuesto de que el hijo perciba ingresos}

El CC en su artículo 152. 3 incluye dentro de las causas de extinción de la pensión el hecho de que «el alimentista [...] haya adquirido un destino o mejorado de fortuna, de suerte que no le sea necesaria la pensión alimenticia para su subsistencia».

En este punto, Pérez MarTín ${ }^{126}$, especifica que el texto del precepto no indica ni la cuantía necesaria para considerar que el hijo ha adquirido independencia económica, ni si el trabajo debe tener carácter permanente o temporal, lo que comporta la necesidad de realizar un estudio de los criterios que los tribunales vienen asumiendo en la práctica para considerar si existe o no causa para la extinción de la pensión alimenticia.

Tres son las situaciones que hemos considerado de mayor relevancia, dentro del amplio elenco existente en la actualidad, en las que se cuestiona si procede o no la extinción de la pensión de alimentos a favor de los hijos mayores de edad, en función de las circunstancias de cada caso concreto. La primera, que el hijo realice sus estudios de forma compaginada con la realización de trabajos de carácter esporádico; la segunda, que realice trabajos de carácter temporal tras la finalización de sus estudios y, finalmente, la tercera que tenga un trabajo de carácter fijo.

Por cuanto atañe a la primera situación, conviene tener en cuenta -conforme a la realidad social- que los hijos, durante la realización de sus estudios -como norma general universitarios-, desempeñan trabajos de carácter esporádico, con la finalidad de obtener unos ingresos que les permitan sufragar parte de los gastos que comporta la realización de éstos, siendo este hecho considerado por la mayoría de los progenitores obligados como una causa determinante para que proceda la extinción de la pensión alimenticia establecida a su favor.

126 La modificación y extinción..., op. cit., pág. 608. 
Asimismo, dos han sido las teorías jurisprudenciales contrapuestas surgidas. Son, de una parte, aquellos pronunciamientos que acertadamente consideran que la realización de trabajos esporádicos, compatibilizados con los estudios no comporta ninguna alteración sustancial, siempre que la falta de finalización de éstos no sea imputable al hijo y, éste continúe su etapa de formación de forma aceptable. Además, el derecho del hijo a percibir la pensión de alimentos no se deberá extinguir por el mero hecho de que éste obtenga algún ingreso realizando trabajos esporádicos, ya que para su extinción se requiere de la existencia de una posibilidad «real» y «concreta»; De otra, la de aquellos otros partidarios en que proceda la extinción de la pensión alimenticia, apoyándose en la edad del hijo y en la circunstancia de que ya debería haber finalizado los estudios, pero sigue realizándolos al mismo tiempo que desempeña este tipo de trabajos.

Postura última, en la que tienen cabida los supuestos en los que el hijo por su avanzada edad y el desempeño de trabajos esporádicos que le reporten una cierta remuneración económica -por ejemplo, trabajos desempeñados durante varios días a la semana- mientras concluye sus estudios, también se dé la circunstancia de que convive en el domicilio de uno de sus progenitores -circunstancia que, en principio, le originará únicamente los gastos personales, los relativos a su sustento y los derivados de sus estudios-.

En virtud de lo anterior, en estas circunstancias lógico sería proceder a la extinción de la pensión alimenticia establecida en favor del hijo mayor de edad, debido a que se podría presumir que el hijo -siempre que estos gastos puedan ser sufragados con los ingresos que percibe-, ha adquirido independencia económica y, por tanto, no necesita la ayuda de su progenitor.

En suma, el hecho de que el hijo mayor de edad desempeñe trabajos durante el periodo estival o los fines de semana compatibilizándolo con la finalización de los estudios, en principio, no debería tener la consideración de causa de extinción de la pensión, debido a que no se puede considerar que éste ha accedido al mundo laboral de forma que le permita gozar de independencia económica. No obstante, la inexistencia de unanimidad por la jurisprudencia menor origina necesario realizar un estudio exhaustivo de cada caso concreto en función de las circunstancias concurrentes, para determinar si procede decretar la extinción o no de la pensión alimenticia.

Por lo que a la segunda situación se refiere, es decir, que el hijo realice trabajos de carácter temporal tras la finalización de sus estu- 
dios, es habitual que la incorporación al mercado laboral se realice a través de este tipo de contratos. Si bien, en este punto la Jurisprudencia menor es coincidente en que en estos casos en los que el hijo mayor de edad ha terminado su formación y se ha incorporado al mercado laboral, desempeñando un trabajo remunerado -ya temporal, ya fijo- que le proporcione una remuneración suficiente para sufragar sus necesidades vitales, debe dejar de percibir la pensión establecida a su favor.

En particular, la Sentencia de la Audiencia Provincial de Cáceres, Sección 1. ${ }^{a}$, de 17 de diciembre de 2003, establece que «no se requiere a los efectos de que proceda declarar extinguida la obligación de alimentos, el que el alimentista desempeñe un trabajo de carácter continuo y efectivo, sino que será suficiente con que ostente una aptitud real para el ejercicio de un oficio, profesión o industria» ${ }^{127}$.

Sin embargo, conforme al amplio abanico de contratos que presenta la legislación laboral, la jurisprudencia sostiene que prudente es realizar un estudio detallado de cada caso concreto, debiendo tener en cuenta para determinar si el supuesto en concreto es o no causa de extinción de la pensión de alimentos una serie de extremos -la cuantía que se perciba por la realización de los mismos, la periodicidad con que se lleven a cabo y la edad con la que cuente el hijo-. Todo ello sin perjuicio de que, en el supuesto de que ésta proceda, en caso de necesidad, los reclame de sus progenitores en un procedimiento independiente.

Respecto al supuesto de que el hijo tenga un empleo de carácter fijo, conviene precisar que las decisiones jurisprudenciales son coincidentes al considerar como una causa automática de extinción de la obligación alimenticia a favor de los hijos el hecho de que éstos obtengan un empleo de carácter fijo -ya en la empresa pública o en la privada-, o se encuentren dados de alta en la Seguridad Social como autónomos, abonando sus cuotas mensuales.

En particular, la Sentencia de la Audiencia Provincial de Cáceres, Sección 1. , de 5 de febrero de 2002 (JUR: 2002/100073), procedió a la extinción de la pensión alimenticia del hijo mayor de edad por el sólo hecho de haber estado dado de alta en el Régimen Especial de Autónomos de la Seguridad Social como trabajador independiente, abonando las correspondientes cuotas a la Seguridad Social, lo que

127 (JUR: 2003/51710). Vid., en los mismos términos, entre otras, las SSAAPP, de Burgos, Sección 2. ${ }^{\text {a }}$, de 18 de febrero de 2008; de Asturias, Sección 4. ${ }^{\text {, }}$, de 16 de enero de 2003 y de 17 de marzo de 2003; de Barcelona, Sección 12. ${ }^{a}$, de 18 de diciembre de 2003 y de Cantabria, Sección 4. ${ }^{\text {a }}$, de 29 de junio de 2006. 
permite presumir que éste disponía de plena autonomía económica y de ingresos propios.

En idéntico sentido, la Sentencia de la Audiencia Provincial de Barcelona, Sección 18. ${ }^{a}$, de 26 de julio de 2004 (JUR: 2004/217396), decretó la extinción de la pensión alimenticia del hijo mayor de edad, alegando que éste disponía de autonomía económica, dado que el trabajo que desempeñaba había dejado de ser de carácter temporal -dejando por tanto de ser éste de carácter esporádico y limitado-, y quedando además constatada su independencia económica, conforme a la documentación aportada en autos, apreciándose, por tanto, que no requería de la ayuda de sus progenitores.

\section{Extinción de la pensión en el supuesto de que el hijo «ni» estudie «ni» trabaje}

Por cuanto atañe a este supuesto, conviene precisar que si el hijo mayor de edad ni estudia ni trabaja por decisión propia, la doctrina ha sido unánime al establecer que este derecho no podrá existir, debido a que del artículo 152. 3 CC se desprende que «la obligación de alimentos cesará cuando el alimentista pueda ejercer un oficio, profesión o industria [...]».

En lo que a esta materia se refiere, en la Sentencia de la Audiencia Provincial de Santa Cruz de Tenerife, Sección 1. ${ }^{a}$, de 12 de junio de 1999, se planteó un supuesto en el que el hijo mayor del matrimonio, ni estudia ni trabaja, por lo que «tal obligación cesa cuando el alimentista pueda ejercer un oficio, profesión o industria [art. 152.3 CC] $y$, por tanto, hay que señalar que él mismo se encuentra en esa situación, de modo que no hay que fijar alimentos a su favor» ${ }^{128}$.

En virtud de lo anterior, se justifica la afirmación que sostiene que si el hijo mayor de edad dejó los estudios, o no los finalizó y, no acredita que padece de una limitación física o psíquica para el trabajo, sea por cuenta propia o ajena, se deberá presumir que el motivo por el que no percibe ingresos es imputable a él, debido a no consta motivo alguno que le impida acceder al mercado de trabajo $^{129} \mathrm{y}$, por tanto, al encontrarse en una situación en que el hijo ni estudia ni tra-

128 (AC: 1999/7496).

129 Siendo este criterio sostenido por la doctrina jurisprudencial menor de forma pacífica y constante, como pone de manifiesto la SAP de Madrid, Sección 24. ${ }^{\text {a }}$, de 31 de octubre de 2002, por la que se procede a la extinción de la pensión alimenticia de una hija mayor de edad al no acreditarse de forma documental que curse ningún tipo de estudios y no constando motivo alguno que le impida el acceso al mercado 
baja, cuando éste sobrepase una determinada edad, estaremos ante una causa de extinción de la pensión alimenticia ${ }^{130}$.

\section{CONCLUSIONES REFLEXIVAS}

Con la redacción inicial del artículo 93 CC se hacía referencia únicamente a los hijos menores de edad, lo que comportó un problema procesal en relación con los hijos mayores de edad o emancipados, admitiéndose su solicitud, ya como «cargas» ya a través del proceso declarativo correspondiente, debido a que en el régimen anterior la mayoría de edad del hijo o la emancipación comportaba la no necesidad de alimentos, por lo que se debían hacer efectivos por el progenitor obligado.

Frente a esta duplicidad de procesos y, con la finalidad de unificar doctrina, la Ley 11/1990, de 15 de octubre, sobre reforma del Código civil, en aplicación del principio de no discriminación por razón de sexo, introduce un segundo párrafo al artículo $93 \mathrm{CC}$, que permite al Juez fijar en la misma resolución los alimentos de los hijos mayores de edad o emancipados que se encuentren carentes de ingresos propios y, residan en el domicilio familiar. Alimentos establecidos por medio del procedimiento matrimonial [arts.142 y ss. CC].

De modo que se realiza una reforma de carácter procesal justificada en que la realidad social ha demostrado que la mayoría de edad no va acompañada de una independencia ni de domicilio familiar ni economía, por lo que inevitablemente el sentido del recurso al juicio de alimentos -conforme al régimen anterior-, pierde su sentido en la medida en que el hijo desde el punto de vista, tanto personal como económico, sigue incardinado en el domicilio familiar.

Respecto de la cuestión de quién ha de ser parte en los procedimientos matrimoniales, precisar que aunque el párrafo segundo del artículo $93 \mathrm{CC}$ reconoce la posibilidad de reclamarlos en este proceso, lo cierto es que no aclara la legitimación procesal para ello. Cuestión salvada por la Sentencia del Tribunal Supremo, Sala de lo Civil, de 24 de abril de 2000, al reconocer de forma expresa la legitimación al cónyuge con el que conviven los hijos mayores de edad para demandar del otro su contribución a los alimentos. Por tanto, el TS unifica

laboral. (El texto de la Sentencia se puede ver en PéREz MARTín, La modificación y extinción..., op. cit., pág. 752).

130 Vid., Pérez Martín La modificación y extinción..., op. cit., pág. 615. 
doctrina, siendo los pronunciamientos posteriores a esta sentencia uniformes al reconocer tal legitimación.

Por cuanto atañe a los alimentos de los hijos mayores de edad en las sentencias de separación o divorcio, conviene matizar que éstos no se deben configurar como cargas derivadas de una situación familiar, ya que son concebidas como un concepto residual -referido únicamente a las cargas del sistema económico matrimonial-, mientras que los alimentos de los hijos encuentran su regulación en los artículos 142 y ss. CC -comprendiendo todo lo indispensable para el sustento, habitación, vestido, educación, asistencia médica e instrucción-.

Respecto a la obligación alimenticia a favor de los hijos mayores de edad, precisar que presenta un régimen jurídico distinto al previsto para los hijos menores de edad, debido a que no es incondicional y, para su concesión se requiere de la acreditación de la necesidad por parte del hijo. De modo que debe ser configurada, como una obligación legal derivada de la vinculación existente entre el alimentante y el alimentista -al existir vínculos de parentesco o de estado- y, mancomunada y divisible, debido a que los hijos mayores de edad o emancipados, aunque ya no se encuentran bajo la patria potestad de sus progenitores, lo cierto es que siguen siendo dependientes económicamente de éstos -ya por estar incursos dentro de un periodo de formación académica, ya por la imposibilidad de incorporase al mercado laboral- y, por tanto, como consecuencia de lo anterior la obligación de alimentos seguirá recayendo sobre ambos progenitores.

Asimismo, la fijación de la cuantía de la prestación alimenticia a favor de los hijos mayores de edad deberá estar en función de las necesidades del hijo y de la proporción en que han de contribuir los obligados a prestarla. Además, corresponderá prestarla a ambos progenitores, ya que ambos presentan la misma proximidad de grado al descendiente. Por otra parte, con la finalidad de evitar una distribución cuantitativamente igualitaria en los supuestos de similitud de ingresos de las partes, lógico sería tener en cuenta el trabajo de atención y asistencia que desarrolla el progenitor conviviente, constituyéndose esta distribución como una contribución en «especie». Atención que aunque se encuentra concretada como una medida previa a la demanda y a los hijos sujetos a patria potestad, lo cierto es que su razón de ser se debería configurar como la misma que en el supuesto de hijos mayores de edad o emancipados, al regularse supuestos similares [art. 4. $1 \mathrm{CC}$ ].

Por su parte, el párrafo segundo del artículo 93 CC prevé para la reclamación de la pensión de alimentos a favor de los hijos mayores 
de edad o emancipados dentro del proceso matrimonial, la necesidad de la concurrencia de dos requisitos. De una parte, la existencia de un proceso sobre nulidad, divorcio o separación; De otra, que el hijo mayor de edad o emancipado conviva en el domicilio familiar y, se encuentre carente de ingresos propios, en el entendido de que estos términos, respectivamente, no deben ser interpretados en sentido estricto o literal, sino en el sentido más amplio de domicilio del progenitor con quien el hijo precisado de alimentos finalmente conviva $\mathrm{y}$, como una falta de independencia económica.

En síntesis, la aplicabilidad del mencionado párrafo requerirá necesariamente de la existencia de un proceso sobre nulidad, separación o divorcio de los progenitores del hijo mayor de edad o emancipado $\mathrm{y}$, de la concurrencia de los requisitos específicos previstos por el precepto, debido a que la inexistencia de cualquiera de ellos comportará que el hijo sólo pueda ejercitar su pretensión alimenticia acudiendo al juicio especial de alimentos provisionales o al juicio declarativo ordinario de alimentos definitivos que corresponda por cuantía.

Pese a que el reconocimiento de la pensión alimenticia a favor de los hijos mayores de edad o emancipados, exige la residencia en el domicilio conyugal o en el de cualquiera de sus progenitores al iniciarse el proceso matrimonial -ya que de contrario, quiebra el requisito exigido por el párrafo segundo del artículo 93 CC-, debido a que la inconvivencia priva al precepto de uno de sus presupuestos aplicativos, lo cierto es que dicho presupuesto se podrá considerar concurrente en los supuestos en los que la ausencia del hijo sea debida a causas justificadas o de carácter transitorio -por ejemplo, el supuesto de ausencia del hijo del domicilio por motivos de estudio- $y$, en consecuencia, si el hijo se viera obligado a residir durante el curso lectivo en un domicilio distinto -siempre que retorne en los periodos vacacionales-, no se podrá alegar como abandono del domicilio familiar o independencia económica y, por tanto, no procederá el cese de la obligación alimenticia, conforme a lo establecido por los artículos 142 y ss. CC.

El hijo mayor de edad con sus estudios culminados, dos son las posiciones jurisprudenciales. De una parte, la que estima que la circunstancia de que el hijo haya completado su formación no comporta la extinción de la pensión, debido a que no implica garantía de independencia económica, puesto que el mero hecho de tener un título no habilita para el ejercicio de una profesión, sino que será necesario contar con una oportunidad para el desempeño de la misma. De otra, los que deniegan la pensión en función de la edad 
que presentan los hijos y de la finalización de unos estudios previos. La pensión debe tener carácter temporal, por lo que no se deberá prestar hasta que el hijo acredite un puesto de trabajo y, por tanto, si esta necesidad proviene de una falta de interés por parte del hijo se presumirá que es por causa a él imputable, procediendo la extinción de los alimentos.

También en los supuestos de continuación de estudios dos han sido las posturas tanto doctrinales como jurisprudenciales claramente diferenciadas. De una parte, aquélla que aunque, en principio, partidaria en el mantenimiento de la pensión de alimentos en los supuestos de hijos que continúan sus estudios con aprovechamiento, con la finalidad de ampliar su formación, lo cierto es que sostiene que la pensión de alimentos no procederá en aquellos casos en los que el hijo tenga una avanzada edad y que por su negligente conducta, la falta de puesto de trabajo o de terminación de sus estudios provoque una carga gravosa para su progenitor, debido a que la continuidad de los estudios no debe depender únicamente de la voluntad del hijo, sino también de la capacidad económica del progenitor; De otra, aquella otra partidaria por el mantenimiento de la pensión de alimentos en los supuestos de hijos mayores de edad que continúan sus estudios, pero con un rendimiento bajo o sin el aprovechamiento debido a que esta causa por sí sola no comporta la extinción del derecho de alimentos concedidos por la vía del párrafo segundo del artículo 93 CC.

En síntesis, en ambos supuestos oportuno será establecer un límite temporal, cifrado en los veintiséis o veintisiete años, sin necesidad de causa que acredite dicha limitación, con la finalidad de que el alimentista tenga constancia de que a partir de una determinada edad deberá valerse por sí mismo. Esto se justifica en que los hijos que cuentan con dicha edad ya suelen haber finalizado sus estudios $\mathrm{y}$, por tanto, se encuentran en circunstancias para poder acceder al mercado laboral, por lo que el mantenimiento de la pensión a partir de dicha edad ya no tiene sentido ni cabida como carga familiar. En todo caso, el hijo trascurrida dicha edad y, en caso de necesidad, podrá reclamar los alimentos a través del procedimiento previsto.

Por otra parte, la carga de la prueba deberá recaer sobre el progenitor que solicita los alimentos para los hijos mayores de edad -es decir, el progenitor conviviente-, debido a que la acreditación de la prueba de la existencia o no de dicha convivencia estará más al alcance de éste - de acuerdo con la «teoría de la facilidad probatoria»- que del progenitor no conviviente. Progenitor último que, 
como norma general, en los supuestos de separación, divorcio o nulidad, desconoce la situación del hijo -al no tener ningún tipo de contacto con el mismo, bien por residir en distinta ciudad o, por omisión de información por parte del hijo o del progenitor conviviente con éste- y, por tanto, este desconocimiento le comporta una mayor dificultad probatoria sobre la no convivencia del hijo en el domicilio del otro progenitor.

Finalmente, la pensión alimenticia de los hijos -establecida conforme al párrafo segundo del artículo 93 CC- no se extinguirá por alcanzar la mayoría de edad, debido a que ésta se mantendrá mientras éstos sigan conviviendo con uno de los progenitores, no conforme a la patria potestad [art. $154 \mathrm{CC}$ ], sino a la «obligación alimenticia entre parientes», siempre que no concurra alguna de las causas de extinción del deber de alimentos [arts. 150 y 152 CC] sin perjuicio, en los supuestos de cese de la pensión, de que acreditada nuevamente la necesidad en un momento posterior por el hijo mayor de edad o emancipado, éste pueda reclamar los alimentos a sus progenitores, pero indudablemente fuera del procedimiento matrimonial.

\section{BIBLIOGRAFÍA CITADA}

AGUILAR RUIZ, Leonor: «El derecho a recibir alimentos de los hijos mayores de edad que voluntariamente abandonan el domicilio familiar. Comentario a la STS de 23 de febrero de 2000», Derecho Patrimonial, núm. 6, 2001, págs. 325-334.

ALBÁCAR LÓPEZ, José Luis y Martín Granizo Fernández, Mariano: Código civil. Doctrina y Jurisprudencia, T. I, Trivium, Madrid, 1991, 2. ${ }^{\mathrm{a}}$ ed.

BELO GONZÁLEZ, Ramón: «Los alimentos de los hijos mayores de edad en el procedimiento matrimonial de sus progenitores», $A C$, núm. 1, 1991, págs. 21-33.

BELTRÁN DE HEREDIA Y ONÍS, Pablo: Comentarios al Código civil y Compilaciones Forales, T. III, Vol. II, Edersa, Madrid, 1978.

CALVO ANTÓN, Manuela: «El nuevo artículo 93 del código civil y el sostenimiento de los hijos en la nulidad, separación o divorcio", La Ley: Revista jurídica española de doctrina, jurisprudencia y bibliografía, núm. 4, 1990, págs. 1106-1125. 
CALAZA LÓPEZ, Sonia; Los procesos matrimoniales. Nulidad, separación y divorcio, Dykinson, Madrid, 2007.

DE MARINO Y GÓMEZ-SANDOVAL, Belén: «La fijación de alimentos para hijos emancipados en los procesos matrimoniales (II)», AC, núm. 3, 1992, págs. 571-583.

DELGADO ECHEVARRÍA, Jesús: Comentario del Código civil, T. I, Ministerio de Justicia, Madrid, 1991.

DÍEZ-PICAZO, Luis, y PONCE DE LEÓN Y GULLÓN BALLESTEROS, Antonio: Sistema de Derecho Civil, Vol. IV, Tecnos, Madrid, 1990.

GONZÁLEZ CARRASCO, Carmen: «Los alimentos de los hijos mayores de edad en los procesos matrimoniales: doctrina de las Audiencias», $A C$, núm. 2, 1998, págs. 23-50.

GONZÁLEZ DEL POZO, Juan Pablo: «Problemas procesales planteados por el nuevo párrafo $2{ }^{\circ}$ del artículo 93 del Código Civil», $A C$, núm. 1, 1991, págs. 163-187.

GUILARTE GUTIÉRREZ, Vicente: «A vueltas con los alimentos de los hijos mayores de edad en la crisis matrimonial de sus progenitores: el artículo 93 párrafo segundo del Código Civil», $A r C$, núm. 3, 1997, págs. 177-190.

JIMÉNEZ MUÑOZ, Francisco Javier: «La regulación española de la obligación legal de alimentos entre parientes», Anuario de Derecho Civil, T. LIX-II, abril-junio, 2006, págs. 743-792.

- «La obligación legal de alimentos entre parientes en España», en Perspectivas del Derecho de Familia en el siglo XXI (XII Congreso Internacional de Derecho de Familia. Conferencias, ponencias e informes publicados), Carlos LASARTE ÁLVAREZ (Dir.), UNED/ IDADFE, Sevilla, 2004, pág. 152.

LASARTE ÁlVAREZ, Carlos: Derecho de Familia. Principios de Derecho Civil, T. IV, Marcial Pons, Madrid, 2012, 11. ${ }^{a}$ ed., págs. 342-354.

LÁZARO PALAU, Carmen María: La pensión alimenticia de los hijos. Supuestos de separación y divorcio, Thompson Aranzadi, Navarra, 2008.

LÓPEZ PELÁEZ, Patricia: «la financiación de la calidad de vida de las personas mayores renta vitalicia y contrato de alimentos», RMTAS, págs. 107-133. 
- «El contrato de vitalicio la cesión de un inmueble a cambio de alimentos», Consultor inmobiliario, 52, 2004, págs. 3-39.

LÓPEZ-MUÑIZ GOÑI, Miguel: El procedimiento contencioso de separación y divorcio: guía práctica y jurisprudencia, Colex, Madrid, 1995, 4. ${ }^{\text {a }}$ ed.

MARÍN GARCÍA DE LEONARDO, María Teresa: Régimen jurídico de

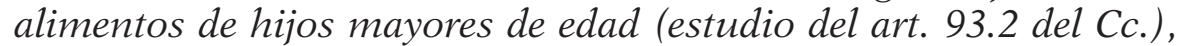
Universitat de València, 1999.

- «La temporalidad de los alimentos de los hijos mayores de edad», Sepin Familia, 2003, págs. 19-26.

MARTÍN NÁJERA, Soledad: «Los alimentos de los hijos mayores de edad en los procesos matrimoniales: El artículo 93.2 y la legitimación», $A C$, núm. 3, 1997, págs. 685-693.

MARTÍNEZ RODRÍGUEZ, Nieves: «Legitimación para reclamar alimentos a favor de los hijos mayores», $A C$, núm. 5, Sección Informe de Jurisprudencia, Quincena del 1 al 15 de marzo, 2008, pág. 590, T. 1. La Ley (La Ley 943/2008), págs. 1-11.

MONDÉJAR PEÑA, M. ${ }^{a}$ Isabel: «La obligación de alimentos y las políticas de la administración española sobre la protección de los mayores y dependientes», Revista jurídica Universidad Autónoma de Madrid, 14, 2006, págS. 128-185.

MONTERO AROCA, Juan: Los procesos matrimoniales: comentarios a la Ley 30/1981, de 7 de julio, sobre los procedimientos en las causas de nulidad, separación y divorcio (comentarios, jurisprudencia y formularios), Tratados y Manuales, Tirant lo Blanch, Valencia, 1997.

- Los alimentos a los hijos en los procesos matrimoniales (La aplicación práctica del artículo 93 CC), Tirant lo Blanch, Valencia, 2002.

MORENO VELASCO, Víctor: «Los alimentos de los hijos mayores de edad en los procedimientos de separación, nulidad y divorcio", Diario La Ley, núm. 7433, 2010, págs. 1-8.

PÉREZ MARTÍN, Antonio Javier: El procedimiento contencioso de separación y divorcio: comentarios, texto legal, casos prácticos, jurisprudencia y formularios de Derecho de familia, T. IV, Lex Nova, Valladolid, 1999, 3. . ed.

- La ejecución de las resoluciones dictadas en procedimientos matrimoniales: comentarios, texto legal, casos prácticos, jurisprudencia 
y formularios de Derecho de familia, T. IV, Lex Nova, Valladolid, 1997, 3. ${ }^{\mathrm{a}}$ ed.

- La modificación y extinción de las medidas. Aspectos sustantivos y procesales. Tratado de Derecho de Familia, T. IV, Lex Nova, Valladolid, 2007.

ROCA I TRÍAS, ENCARNA: «Comentario al artículo 93 del Código civil», en Comentario al Código civil, Ministerio de Justicia, T. I, Madrid, 1993.

TERRADEZ MURILLO, Carmen: «Las pensiones alimenticias de los hijos mayores de edad: legitimación para su reclamación», Revista general de derecho, Vol. 56, núm. 675, 2000, págs. 14505-14517.

RIVERO HERNÁNDEZ, Francisco: Matrimonio y divorcio. Comentarios al Título IV del Libro Primero del Código civil, (coord.), José Luis LACRUZ BERDEJO, Civitas, Madrid, 1994.

RUIZ-RICO RUIZ-MORÓN, Juan: «La fijación de alimentos a hijos mayores de edad o emancipados al amparo del párrafo segundo del artículo 93 CC», $A C$, núm. 1, 1993, págs. 1943-1962.

VALLADARES RASCÓN, Etelvina: Nulidad, separación, divorcio. Comentarios a la Ley de reforma del matrimonio, Civitas, Madrid, 1982, 2. ${ }^{\mathrm{a}} \mathrm{ed}$.

VÁZQUEZ YRUZUBIETA, Carlos: Régimen jurídico de la celebración $y$ disolución del matrimonio: Ley 30/1981, de 7 de julio (Monografías), Edersa, Madrid, 1981.

VEIGA NICOLE, Elisa: «La pensión de alimentos en la Ley 30/1981, de 7 de julio", en Problemas candentes en los procesos de familia, Madrid, 1995, págs. 119-140. 
